\title{
GESTÃO ORGANIZACIONAL: PROPOSTA DE UM MÉTODO DE AVALIAÇÃO SOB A ÓTICA DO CONCEITO DE ENTROPIA ORGANIZACIONAL
}

Cleide L. Carvalho

admclcarvalho@gmail.com Universidade Federal Fluminense

- UFF, Niterói, Rio de Janeiro, Brasil

\section{Stella Regina Reis da Costa} stella@ufrrj.br Universidade Federal Fluminense - UFF, Niterói, Rio de Janeiro, Brasil

\section{RESUMO}

A evolução do conhecimento científico durante séculos possibilita cada vez mais a integração das ciências exatas e humanas em prol de um único objetivo. A aplicação dos princípios da termodinâmica em sistemas abertos torna a compreensão da gestão organizacional mais próxima da essência dos sistemas e possibilita inferir sobre seu funcionamento dinâmico. $O$ objetivo desta pesquisa foi desenvolver um método de avaliação para elevar o nível de compreensão das práticas de gestão, sob a ótica da entropia em sistemas abertos para proporcionar ao gestor um panorama do ambiente interno e externo da organização em seu contexto. Foi realizado um levantamento por meio de amostragem por conveniência em uma população de especialistas-consultores empresariais que atuam em entidades privadas, pequenas, médias e grandes organizações nacionais e internacionais, bem como profissionais autônomos que atuam na prestação de serviço de consultoria empresarial, com foco em gestão organizacional, estratégia organizacional, liderança, processos de negócios, desenvolvimento organizacional, inovação e sustentabilidade no estado do Rio de Janeiro. Através do método proposto poder-se-á compreender os fatores intrínsecos à gestão que gerem maior ou menor ganho ou perda de energia, o que poderá contribuir para tomada de decisão, criando um ambiente fértil às mudanças.

Palavras-chave: Entropia; Liderança, Estratégia; Gestão. 


\section{INTRODUÇÃO}

A utilização dos fundamentos da termodinâmica nas ciências sociais deve ser realizada evitando o emprego, impreciso ou equivocado, de seus conceitos, que possam gerar ambiguidades, bem como permitir o uso do conhecimento de uma área da ciência em outra. Deve respeitar o conceito original e contemplar uma analogia ponderada, ainda que, no caso da entropia, o estado da arte exija ser mantida, explicitando-se a tipologia empregada, como a entropia termodinâmica, de Clausius, em que energia do universo permanece constante, enquanto a entropia do universo em todos os momentos se move em direção ao máximo.

A entropia negativa ou negentropia pode ser definida como o déficit específico de entropia de um subsistema em relação ao caos circundante. Entropia negativa é usada em informações teóricas para medir a distância até a normalidade. Mede a diferença de entropia entre uma determinada distribuição e a distribuição gaussiana, que é a distribuição com maior entropia (Santamaría- bonfil et al., 2016).

Será empregado como base desta pesquisa o conceito de Bruyn et al. (2014), de que a entropia, como expressa na segunda lei da termodinâmica, é um princípio fundamental nas ciências tradicionais da engenharia e embora muitas versões existam, tem basicamente a intenção de expressar a crescente quantidade de complexidade, incerteza (falta de informação) e a tendência das partículas para interagir dentro de um sistema.

A compreensão da dinâmica dos sistemas sociais torna possível previsões e modelagem do estado futuro do sistema organizacional com menor margem de erro. No século XXI, as demarcações geográficas perderam importância, exigindo uma abordagem diferenciada das que foram aplicadas no século passado. As lideranças empresariais necessitam aprimorar suas capacidades para gerir em um ambiente instável e imprevisível (Olyaiy, 2015).

No ambiente globalizado, a alta gestão e níveis médios de comando devem direcionar suas ações com base em informações e dados confiáveis. As pessoas representam o elo entre as estratégias definidas e a base que as sustentam. A eficiência e eficácia das decisões dependem do quão as pessoas compreendem e operacionalizam os processos de uma organização, bem como lidam com as interfaces de seus ambientes, internamente e externamente.

As organizações, como sistemas abertos, sofrem as mesmas transformações que ocorrem em sistemas mecânicos. A quantidade de energia que sai de uma organização (trabaIho de valor agregado) é igual à quantidade de energia que se coloca, menos a quantidade de energia necessária para manter a organização em funcionamento (Barrett, 2010b).
Assim, é primordial que líderes, como agentes de mudança, saibam quais são os fatores que impactam a organização, conhecendo-os e considerando-os em suas tomadas de decisões. A partir dessa abordagem, torna-se importante compreender a entropia corporativa.

Não obstante, é recorrente que organizações possuam estratégias que não sejam devidamente esclarecidas, discutidas e não alcancem todos os níveis. Tais fatores podem conduzir a tomada de decisões inconsistentes para o sucesso do negócio. A análise do desempenho organizacional, meramente com base em modelos quantitativos, não oferece uma visão inteira da situação do sistema de gestão e de seus processos de negócios (Mcauley et al., 2013).

A sustentação desse estudo são os postulados científicos das ciências exatas e suas aplicações nas ciências humanas, com o propósito de satisfazer a premissa na qual a gestão estratégica nas organizações está em um sistema aberto. As organizações são diretamente impactadas pelas leis que regem o universo e por consequência, devem considerá-las em suas tomadas de decisões. A abrangência do pensamento sistêmico dentro do contexto organizacional e suas inter-relações com o ambiente interno e externo geram interações que podem ser positivas ou negativas, de maneira que pode afetar e ser afetada em suas decisões.

O objetivo desta pesquisa foi desenvolver um método de avaliação para elevar o nível de compreensão das práticas de gestão sob a ótica da entropia em sistemas abertos, com o intuito de compreender os principais fatores que impactam a entropia organizacional. Procurou-se demonstrar como as organizações podem adotar os princípios da entropia nas estratégias organizacionais e ainda identificar fatores intrínsecos à gestão, que gerem mais ou menos ganho ou perda de energia corroborando para o alcance do objetivo proposto.

\section{FUNDAMENTAÇÃO TEÓRICA}

O processo econômico consiste materialmente em uma transformação de baixa para alta entropia, ou seja, em perdas. Uma vez que esta transformação é irrevogável, os recursos devem necessariamente representar uma noção de valor, seja econômico ou não. Visto que o processo de gestão é um conjunto de necessidades e expectativas, as ações de todos os agentes, humanos ou materiais, estão relacionados ao ambiente e à sociedade, o que permite destacar as diferenças entre sistemas de gestão que fracassam e outros que prosperam ao longo dos anos, ou até negócios que são mantidos através dos séculos (Gray, 2013).

A lei da entropia possibilita captar a evolução e consequências geradas pelas ações operacionais e estratégicas de uma organização devido às pressões de suas partes in- 
teressadas (sociedade, governo, fornecedores, acionistas, conselhos administrativos, funcionários e organizações não governamentais) e todos que se sentirem afetados internamente ou externamente. Uma organização é a coordenação racional das atividades de várias pessoas para a realização de objetivo implícito ou explícito, através da divisão de trabalho ou função, bem como através de uma hierarquia de autoridade e responsabilidade.

Para Mcauley et al. (2013), muitos escritores contemporâneos sugerem que, em qualquer organização moderna típica há uma elite de gerentes e profissionais que são capazes de usar seu intelecto e racionalidade na busca de seu trabalho, além de sustentar os funcionários, para quem o trabalho é essencialmente a fonte de sobrevivência. 0 tratamento dado às organizações como sistema fornece a oportunidade de aproximar a ciência da gestão da ciência natural, podendo estabelecer métodos e técnicas da engenharia para o controle organizacional a partir de princípios, como compreendem os autores Mcauley et al. (2013).

A Teoria de sistemas fornece uma rica oportunidade para desenvolver um entendimento dos princípios que se aplicam a todas as organizações. Fornece uma estrutura intelectualmente rigorosa para a exploração das organizações. Quando chegarmos à Teoria de sistemas abertos, podemos explorar a relação entre a organização e seu ambiente externo. Isto fornece uma estrutura racional para lidar com as incertezas que um destino inconstante lança nas organizações (Mcauley et al., 2013, p. 104).

A organização é um conjunto de pessoas que influenciam no nível de energia do sistema, sendo alguns fatores inerentes a cada indivíduo, que são partes do todo.

Assim, todos os envolvidos têm conhecimento das aspirações e objetivos individuais dentro da organização, fazendo com que a integração entre os variados níveis e posições sejam inevitáveis para se alcançar o que é planejado ou definido pelos níveis superiores. Esse processo é denominado de latência, ou seja, como são gerados, garantidos e mantidos, gerando a cultura organizacional (Mcauley et al., 2013). Além disso, a organização pode mudar conforme suas necessidades para manter o equilíbrio ou seguir outro trajeto de modo a tornar-se ainda mais equilibrada.

Os estudos dos sociólogos Anselm Strauss e Barney Glaser (1967) descrevem "os processos de 'gerenciamento' de pacientes que têm doenças crônicas à medida que passam pelos estágios de recuperação, como o que ocorre nas organizações de alta entropia, ou seja, ocorre uma evolução". Esses estudos encontraram aplicações em diversas áreas do conhecimento, como nas organizações. Partindo desse princípio, dentro da organização, a "trajetória de mudança" (Figura 1) pode ser entendida e analisada com base nos diferentes estágios que as pessoas, grupos e organizações vivenciam no processo de mudança (Mcauley et al., 2013).

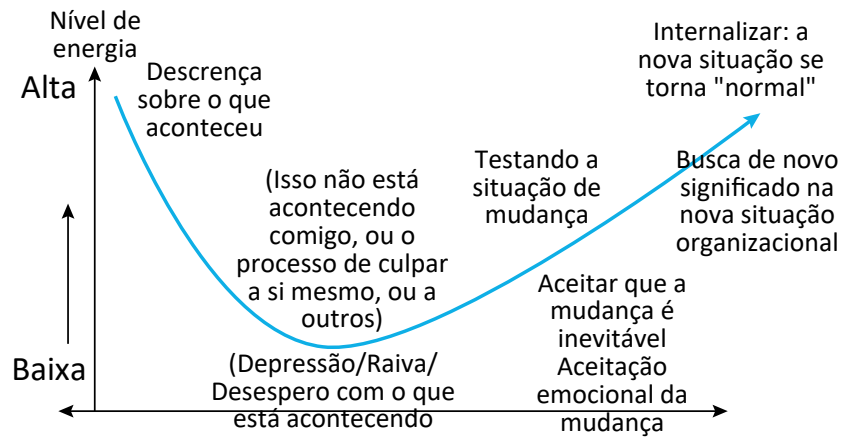

Figura 1. Trajetória da mudança e nível de energia Fonte: Mcauley et al. (2013, p. 31)

- A entropia é a essência e dependente de massa: dois quilos de qualquer substância têm exatamente o dobro de entropia de um quilo da mesma substância em iguais condições termodinâmicas. Elementos intangíveis não têm entropia (quer positiva quer negativa). Jing (2011) salienta três pontos a serem considerados inter-relacionados e intransferíveis na gestão organizacional, no aspecto da entropia, sendo:

- A entropia da escala da empresa: como um sistema organizacional, seus fatores têm uma hierarquia diferente e uma estrutura funcional. Há várias relações entre esses fatores, isto é, o sistema empresarial é incerto. Juntamente com a ampliação da escala empresarial, os fatores se tornam cada vez mais desafiadores. O número de fatores que compõem o sistema corporativo, isto é, a escala da empresa, afeta a entropia.

- A capacidade da entropia da empresa: consiste nas habilidades de sobrevivência do mercado e da operação de gestão, que são a estrutura, extensão e força da capacidade do núcleo. Com o crescimento constante, as informações externas e os fatores do sistema corporativo tornam-se cada vez melhores.

- A entropia de velocidade da empresa: o desenvolvimento da empresa pode ser considerado como absorção e fusão de todos os tipos de informações, finanças, assuntos e funcionários. Quando a empresa cresce rapidamente, ocorrem todos os tipos de fenômenos como, o número de funcionários, finanças, desempenho de vendas e crescimento. Quando as capacidades organizacionais estão fracas, a entropia tem um relacionamento curvo $U$ invertido 
com o empreendedorismo corporativo, e, quando as capacidades organizacionais são fortes, a relação entre entropia e empreendedorismo corporativo é significativamente positiva (Gohil; Deshpande, 2014). A eficiência e funcionalidade de um sistema de gestão podem ser refletidas usando a entropia de gerenciamento. Tomando isso como uma condição prévia, a interpretação da gestão da segunda lei da termodinâmica pode ser descrita como a estabilidade dos requisitos dos elementos do sistema, como estrutura ou outros fatores, que resultará no atraso do sistema em relação ao ambiente externo, o que determina uma falha gradual de funcionalidade da administração, pois as reações do sistema não podem responder imediatamente às mudanças do seu ambiente. Como consequência, a entropia aumenta (Ali et al., 2017). -O ambiente externo de uma organização pode ser dividido em ambiente específico e ambiente geral. $\mathrm{O}$ ambiente específico influencia diretamente a decisão e a ação do gestor, e é diretamente relevante para a realização dos objetivos organizacionais (Chun et al., 2013).

\section{METODOLOGIA}

Os respondentes foram selecionados a partir da conveniência dos autores, tendo como foco as áreas de atuação dos respondentes, permitindo que suas experiências pudessem de maneira mais significativa contribuir para a pesquisa, visando uniformizar ao máximo possível a amostra. Foram selecionados 26 respondentes de diversas áreas de conhecimento relacionadas à gestão empresarial. A diversidade geográfica dos respondentes pode ser verificada por suas localizações, bem como o tipo de empresas em que atuam, tendo sido possível abranger $46 \%$ de profissionais que influenciam pequenas, médias e grandes empresas; $31 \%$ formado por consultores-auditores-empreendedores; e $23 \%$ de consultores independes/autônomos, que atuam em organização governamental de apoio ao empresariado.

Os respondentes foram distribuídos em: $31 \%$ na cidade do Rio de Janeiro; $19 \%$ em Araruama; $12 \%$ em Volta Redonda; $12 \%$ em Niterói; $11 \%$ em Campos dos Goytacazes; $11 \%$ em Macaé; e 4\% em Petrópolis. Todos os municípios são do Estado do Rio de Janeiro, conforme Figura 2.

No que tange a formação acadêmica: $85 \%$ possuem mestrado ou são mestrandos; $8 \%$ são doutores ou doutorandos; e $8 \%$ possuem apenas graduação. Referente ao perfil de gênero: $38 \%$ formado por mulheres e $62 \%$ por homens. A Figura 3 mostra a categoria profissional com tempo de atuação como consultores.

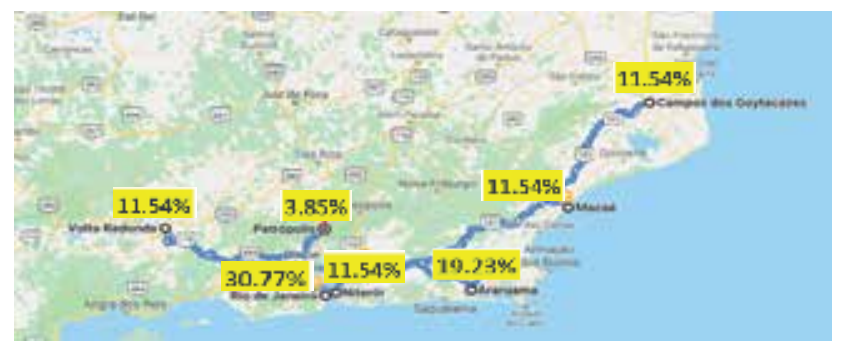

Figura 2. Localização dos respondentes por cidade no estado do Rio de Janeiro

Fonte: elaborada pelos autores (2020).

Tempo de atuação como profissionais consultores

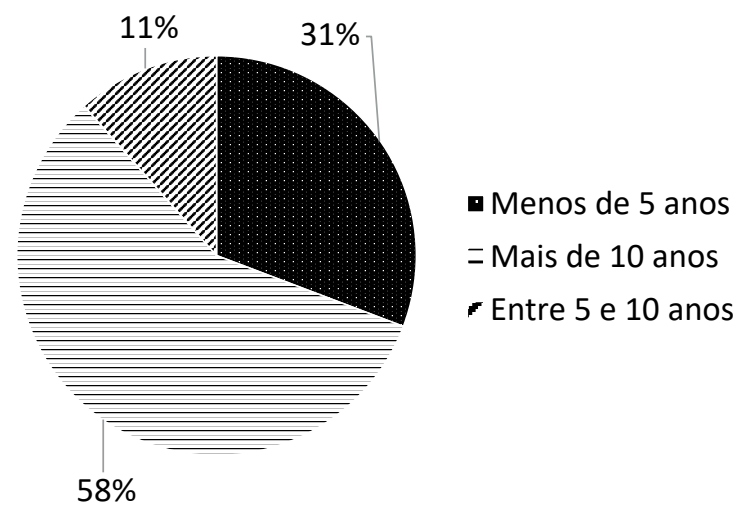

Figura 3. Tempo de atuação como profissionais consultores Fonte: elaborada pelos autores (2020).

O nível acadêmico dos respondentes é apresentado na Figura 4, onde $86.4 \%$ possuem mestrado ou estão cursando, $7.7 \%$ são doutorandos ou possuem doutorados e respectivamente $7.7 \%$ possuem somente graduação.

Perfil acadêmico dos respondentes

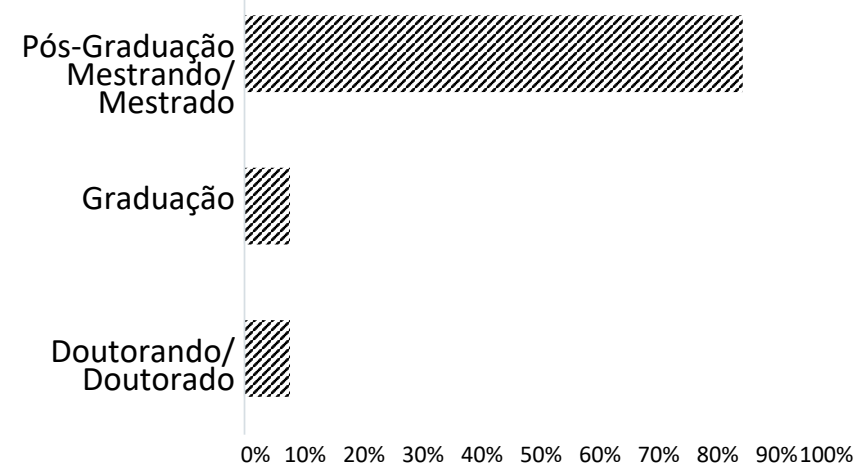

Figura 4. Caracterização da amostra utilizada na pesquisa Fonte: elaborada pelos autores (2020). 
A estratificação dos resultados visou dividir os dados em diferentes níveis, obtendo o maior volume de informações, elevando o grau de profundidade da análise e identificando as variáveis que poderiam impactar menos ou mais no nível de entropia através das respostas obtidas.

A escala foi dividida em cinco níveis de pontuação. A cada categoria de resposta foi atribuído um peso equivalente, numa escala de 1 a 5 , onde a entropia cresce à direita e decresce à esquerda (Figura 5).

\begin{tabular}{|c|c|c|c|c|}
\hline \multicolumn{5}{|c|}{ Níveis de impacto da Entropia sobre a organização e quantificação } \\
\hline $\begin{array}{c}\text { Nível } 1 \\
\text { Primário }\end{array}$ & $\begin{array}{c}\text { Nível } 2 \\
\text { Baixo }\end{array}$ & $\begin{array}{c}\text { Nível } 3 \\
\text { Significativo }\end{array}$ & $\begin{array}{l}\text { Nível } 4 \\
\text { Sério }\end{array}$ & $\begin{array}{l}\text { Nível } 5 \\
\text { Crítico }\end{array}$ \\
\hline \multicolumn{5}{|c|}{ Respostas dos respondentes } \\
\hline \multirow[t]{2}{*}{$\begin{array}{l}1 \\
-\end{array}$} & \multicolumn{3}{|c|}{ Nível de entropia } & $\begin{array}{r}5 \\
+\end{array}$ \\
\hline & \multicolumn{4}{|c|}{ Escala de equivalência com nível de entropia } \\
\hline$(\leq 10 \%)$ & $(11 \%-2 c)$ & $(21 \%-30 \%$ & $(31 \%-4$ & $(41 \%+)$ \\
\hline
\end{tabular}

Figura 5. Níveis de impacto da Entropia sobre a organização e quantificação

Fonte: elaborada pelos autores (2020) com base em (Barret, 2010b).

Com base no modelo de (Barret, 2010b), o estudo proporcionou uma abordagem sistêmica em todas as fases do tratamento, análise e discussão dos resultados, considerando as entropias social, organizacional, pessoal, informacional e cultural. Barrett (2010b) discorre sobre o que ocorre com os sistemas mecânicos e vale também para sistemas humanos, como as organizações. A quantidade de energia que sai de uma organização (trabalho de valor agregado) é igual à quantidade de energia que se coloca, menos a quantidade de energia necessária para manter a organização em funcionamento.

Nesse caso, o grau de disfunção ou distúrbio em uma organização é alto, devido a fatores, tais como: controle excessivo, cautela, confusão, burocracia, hierarquia, concorrência e culpa, gerando uma demanda maior de energia para que os empregados tenham suas atividades concluídas. Essa energia adicional é chamada de entropia, porque é causada por fatores que são endêmicos para a cultura da organização. A energia envolvida na superação da entropia cultural é uma energia que não está disponível para trabalho como valor agregado (Barrett, 2010a).

$<10 \%$ : Nível primário - este é um baixo nível de entropia.

11\% - 20\% - Questões menores: Este nível de entropia cultural reflete questões que requerem ajuste estrutural. É importante reduzir o nível de entropia cultural para melhorar o desempenho.

21\% - 30\% - Questões significativas: Este nível de entropia cultural reflete questões significativas requerendo transformação cultural, estrutural e coaching de liderança. Isto é importante para reduzir o nível de entropia cultural para melhorar o desempenho.

31\% - 40\% - Questões sérias: este nível reflete sérios problemas e requer desenvolvimento da liderança, transformação na estrutura e estrutura organizacional.

41\%+ - Questões críticas: este nível reflete problemas críticos, que demandam mudanças na liderança, reestruturação da estrutura, cultura e desenvolvimento de novas estratégias para desenvolvimento dos líderes (Barrett, 2010b).

Cada questão foi analisada separadamente, em comparação com o padrão da escala definida no questionário, e as medidas numéricas de posição (Equação 1) foram obtidas através da média ponderada entre quantidade de quantificadores apontados pelos respondentes e o peso a eles atribuídos, além de servir como balizador do método para sua validação, indicando sua proporcionalidade. Quando a média cai a entropia também é reduzida.

Foram adotadas dez questões: Q1; Q2; Q3; Q4; Q5; Q6; Q7; Q8; Q9 e Q10 (Figura 6). Destaca-se que os resultados exprimem os pontos de vistas dos profissionais respondentes, bem como podem apresentar variação pertinente devido ao volume de informações que os atingem cotidianamente e a dinâmica do tema em constante transformação. Os dados coletados são apresentados em seções de 1 a 5 , sendo 1- gestão, 2- liderança, 3- estratégia, 4- cultura organizacional e 5- práticas operacionais.

O processo de construção do cálculo do método de avaliação quali-quanti da entropia organizacional foi sob a ótica da entropia e está norteado pelos níveis de entropia propostos por Barret (2010b), sendo empregado no tratamento dos dados.

O método de avaliação do Nível de Entropia Organizacional (NEo), adotado neste estudo, contempla aspectos quantitativos e qualitativos, empregando a estatística descritiva como suporte para análise e tratamento dos dados. A essência do método está na abordagem holística e multidisciplinar da organização, além de suas conexões endógenas e exógenas. É aplicável a qualquer tipo, porte e natureza de negócio. A metodologia para o cálculo da entropia baseia-se na entropia cultural já existente e a partir dessa, desenvolve-se padrões e parâmetros próprios para o método NEo. 


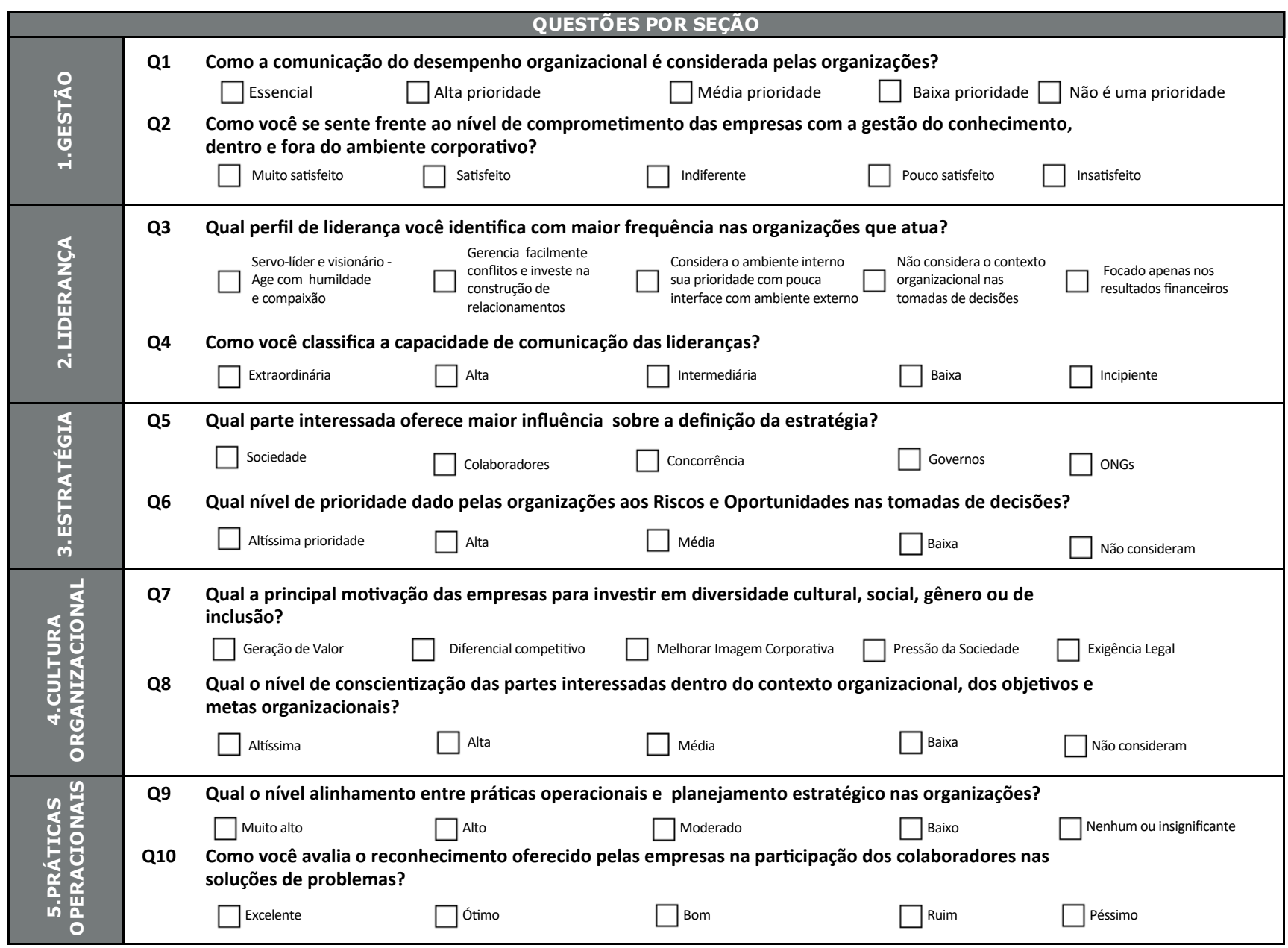

Figura 6. Perguntas por seção adotadas na pesquisa Fonte: elaborada pelos autores (2020) com base em (Barret, 2010b).

$$
\mathrm{NEo}=\frac{\sum \dot{\mathrm{x}} \cdot \mathrm{i} / 100^{2}}{\mathrm{Nqo}}
$$

Em que,

NEo : nível de entropia organizacional (\%)

$$
\sum=\text { soma }
$$

$\dot{x}$ : quantidade do quantificador $i$ (número absoluto de respondentes para cada quantificador)

$\dot{w}$ : peso atribuído ao quantificador $i$
Nqo: quantidade total de quantificadores empregados na pesquisa

Tomando como exemplo, o resultado de uma pesquisa hipotética, com uma amostra de 30 respondentes, pode-se demonstrar o emprego do método. Assim, quando questionado aos respondentes sobre o nível de investimento em diversidade, o pesquisador obteve o seguinte resultado: 11 respondentes afirmaram ser "Essencial"; 13 "Alta prioridade"; e 6 "Média prioridade". Desta forma, o cálculo resultante é demonstrado no quadro 1.

Ao comparar os resultados com o padrão qualitativo empregado, conclui-se que o nível de entropia está no nível 2 de $11 \%-20 \%$, com questões menos graves, requerendo ajustes pela liderança para melhorar o desempenho da organização. 
Quadro 1. Exemplo de cálculo do nível de entropia para quanti-qualificação-Pesquisa hipotética

\begin{tabular}{|c|c|c|c|c|c|c|c|c|c|c|c|c|c|c|}
\hline \multirow[t]{2}{*}{$\begin{array}{l}\text { Ques- } \\
\text { tão }\end{array}$} & \multicolumn{2}{|c|}{ Essencial } & \multicolumn{2}{|c|}{$\begin{array}{c}\text { Alta priori- } \\
\text { dade }\end{array}$} & \multicolumn{2}{|c|}{$\begin{array}{l}\text { Média priori- } \\
\text { dade }\end{array}$} & \multicolumn{2}{|c|}{$\begin{array}{l}\text { Baixa priori- } \\
\text { dade }\end{array}$} & \multicolumn{2}{|c|}{$\begin{array}{l}\text { Não é uma } \\
\text { prioridade }\end{array}$} & \multirow{2}{*}{$\begin{array}{c}M p= \\
\sum w i x i \\
/ \sum w i\end{array}$} & \multirow{2}{*}{$\sum$ WiXi } & \multirow[t]{2}{*}{$\mathrm{Nqo}$} & \multirow[t]{2}{*}{$\begin{array}{c}\text { Score } \\
\% \\
\text { NEo }\end{array}$} \\
\hline & $X i$ & Wi & $X i$ & Wi & $X i$ & Wi & $X i$ & Wi & $X i$ & $\mathrm{Wi}$ & & & & \\
\hline Q1 & 11 & 1 & 13 & 2 & 6 & 3 & 0 & 4 & 0 & 5 & 3,7 & 55,0 & 5,0 & 11 \\
\hline
\end{tabular}

Cálculo Mp $=\sum$ wixi $/ \sum$ wi $=((1 * 11)+(2 * 13)+(3 * 6)+(4 * 0)+(5 * 0)) / 15=3,7$

$\sum \mathrm{WiXi}=(1 * 11)+(2 * 13)+(3 * 6)+(4 * 0)+(5 * 0=55,0$

Score $\%$ NEo $=\left(\sum \mathrm{WiXi} / 100\right) / \mathrm{Nqo}=(55 / 100) / 5=0,11=11 \%$

Fonte: elaborado pelos autores (2020) com base em (Barret, 2010b).

\section{RESULTADOS E DISCUSSÃO}

\section{Gestão}

As Figuras 7 e 8 apresentam os resultados absolutos qualitativos quanto a importância da comunicação do desempenho organizacional, quando $42 \%$ consideraram que as organizações têm a comunicação como essencial, $23 \%$ média prioridade, $27 \%$ baixa prioridade e $8 \%$ como alta prioridade. No que concerne ao nível de comprometimento das empresas com a gestão do conhecimento, $77 \%$ dos respondentes se consideram "pouco satisfeito" e $8 \%$ "insatisfeito".

\section{Comunicação e desempenho organizacional}

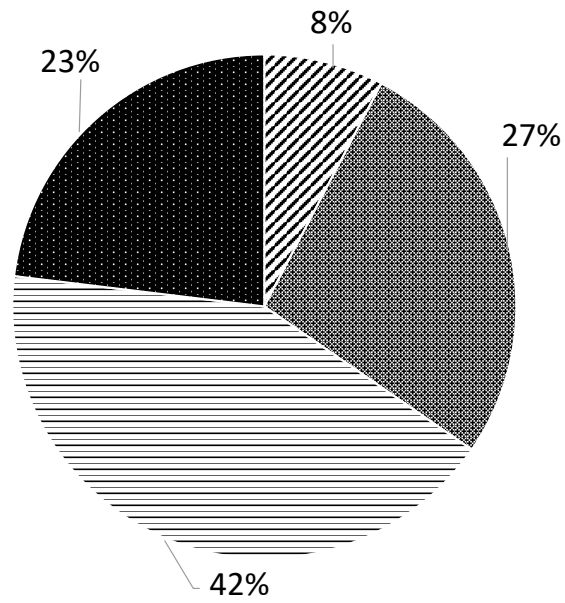

$\begin{array}{ll}\text { Alta prioridade } & - \text { Essencial } \\ \text { Baixa prioridade } & \text { Média prioridade }\end{array}$

Figura 7. Importância da comunicação do desempenho organizacional

Fonte: elaborada pelos autores (2020).

Na visão de Mcauley et al. (2013), não é incomum que as organizações possuam um planejamento estratégico fechado, que não seja comunicado ou compartilhado com os níveis tático e operacional. E esse fator favorece um ambien- te de tomadas de decisões inconscientes sem base factual, gerando prejuízos ao desempenho da organização e consequentemente eleva o grau de risco e perdas.

Nível de satisfação com gestão do conhecimento nas organizações

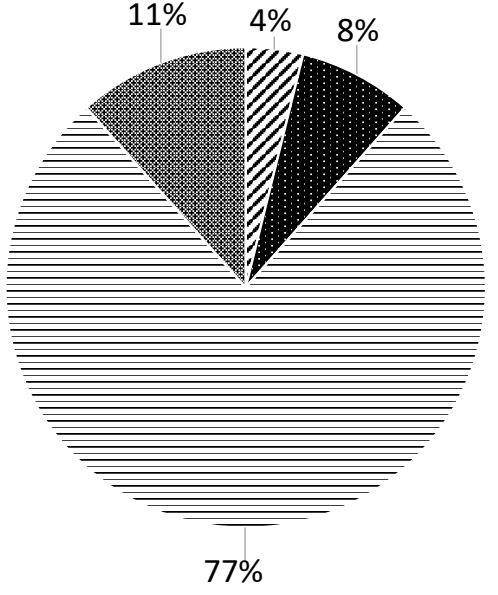

$$
\begin{array}{ll}
\text { - Indiferente } & \text { - Pouco satisfeito } \\
\text { - Insatisfeito } & \text { Satisfeito }
\end{array}
$$

Figura 8. Nível de satisfação com gestão do conhecimento nas organizações

Fonte: elaborada pelos autores (2020).

Quando Ben (2016) publicou a citação de G. N. Lewis (1930) de que: "Ganho na entropia sempre significa perda de informação e nada mais", nos proporciona analisar o resultado da insatisfação dos respondentes acerca da importância dada à comunicação do desempenho organizacional às partes interessadas.

Quando não se tem um contexto de organização bem definido e as partes interessadas devidamente identificadas, bem como seus interesses sobre a organização adequadamente mapeados, dificilmente será possível ter uma boa comunicação, pois não se sabe quem são e quais seus interesses. Não se pode comunicar apropriadamente (Markina; Dyachkov, 2014). 


\begin{tabular}{|c|c|c|c|c|c|c|c|c|c|c|c|c|c|c|}
\hline \multirow[t]{2}{*}{$\begin{array}{l}\text { Ques- } \\
\text { tão }\end{array}$} & \multicolumn{2}{|c|}{ Essencial } & \multicolumn{2}{|c|}{ Alta prioridade } & \multicolumn{2}{|c|}{$\begin{array}{c}\text { Média priori- } \\
\text { dade }\end{array}$} & \multicolumn{2}{|c|}{$\begin{array}{l}\text { Baixa priori- } \\
\text { dade }\end{array}$} & \multicolumn{2}{|c|}{$\begin{array}{l}\text { Não é uma } \\
\text { prioridade }\end{array}$} & \multirow{2}{*}{$\begin{array}{c}M p= \\
\sum \text { wixi / } \\
\sum \text { wi }\end{array}$} & \multirow[t]{2}{*}{$\sum$ WiXi } & \multirow[t]{2}{*}{ Nqo } & \multirow{2}{*}{$\begin{array}{l}\text { Score } \\
\% \text { NEo }\end{array}$} \\
\hline & $\mathrm{Xi}$ & Wi & $\mathrm{Xi}$ & Wi & $\mathrm{Xi}$ & Wi & $\mathrm{Xi}$ & Wi & $\mathrm{Xi}$ & Wi & & & & \\
\hline Q1 & 11 & 1 & 2 & 2 & 6 & 3 & 7 & 4 & 0 & 5 & 4,1 & 61,0 & 5,0 & 12,2 \\
\hline \multirow{3}{*}{$\begin{array}{l}\text { Cálcu- } \\
\text { lo }\end{array}$} & \multicolumn{14}{|c|}{$\mathrm{Mp}=\sum$ wixi $/ \sum \mathrm{wi}=((1 * 11)+(2 * 13)+(3 * 2)+(4 * 0)+(5 * 0)) / 15=4,1$} \\
\hline & \multicolumn{14}{|c|}{$\left.\sum \mathrm{WiXi}=(1 * 11)+(2 * 2)+(3 * 6)+(4 * 7)+5 * 0\right)=61,0$} \\
\hline & \multicolumn{14}{|c|}{ Score $\% \mathrm{NEo}=\left(\sum \mathrm{WiXi} / 100\right) / \mathrm{NqO}=(61 / 100) / 5=0,122=12,2 \%$} \\
\hline \multirow[t]{2}{*}{$\begin{array}{l}\text { Ques- } \\
\text { tão }\end{array}$} & \multicolumn{2}{|c|}{ Muito satisfeito } & \multicolumn{2}{|c|}{ Satisfeito } & \multicolumn{2}{|c|}{ Indiferente } & \multicolumn{2}{|c|}{ Pouco satisfeito } & \multicolumn{2}{|c|}{ Insatisfeito } & \multirow{2}{*}{$\begin{array}{c}M p= \\
\sum w i x i / \\
\sum w i\end{array}$} & \multirow{2}{*}{$\sum$ WiXi } & \multirow[t]{2}{*}{ Nqo } & \multirow{2}{*}{$\begin{array}{l}\text { Score } \\
\% \text { NEc }\end{array}$} \\
\hline & $\mathrm{Xi}$ & $\mathrm{Wi}$ & $\mathrm{Xi}$ & Wi & $\mathrm{Xi}$ & $\mathrm{Wi}$ & $\mathrm{Xi}$ & $\mathrm{Wi}$ & $\mathrm{Xi}$ & Wi & & & & \\
\hline Q2 & 0 & 1 & 3 & 2 & 1 & 3 & 20 & 4 & 2 & 5 & 6,6 & 89,1 & 5,0 & 17,8 \\
\hline \multirow{3}{*}{$\begin{array}{l}\text { Cálcu- } \\
\text { lo }\end{array}$} & \multicolumn{14}{|c|}{$\mathrm{Mp}=\sum \mathrm{wixi} / \sum \mathrm{wi}=\left((1 * 0)+(2 * 3)+\left(3^{*} 1\right)+(4 * 20)+(5 * 2)\right) / 15=6,6$} \\
\hline & \multicolumn{14}{|c|}{$\sum \mathrm{WiXi}=(1 * 0)+(2 * 3)+(3 * 1)+(4 * 20)+(5 * 2)=89,1$} \\
\hline & \multicolumn{14}{|c|}{ Score $\% \mathrm{NEo}=((\mathrm{WiXi} / 100) / \mathrm{Nqo}=(89,1 / 100) / 5=0,178=17,8 \%$} \\
\hline
\end{tabular}

Quadro 2. Estratificação Questões Q1 e Q2

Fonte: elaborado pelos autores (2020).

Para Q1, Mp=4.1 e nível de entropia de $12.2 \%$, aponta um nível de entropia entre $11 \%-20 \%$, está mais próximo de atingir o nível primário; já Q2, apresenta uma $\mathrm{Mp}=6.6$ e um nível de entropia de $17.8 \%$, o que remete ao nível 2 de baixa entropia (11\%-20\%), sinalizando necessidade de melhorias (Quadro 2).

Para aprimorar a gestão e alcançar um equilíbrio, se faz necessário elevar o nível de comprometimento da liderança com as questões relacionadas à gestão do conhecimento. Ações práticas podem englobar maior investimento das organizações em treinamento e desenvolvimento, implementação de plataformas digitais de compartilhamento de dados e informações, criando interface entre o ambiente interno e externo (Martínez-Berumen et al., 2014; Santamaría-bonfil et al., 2016).

As organizações podem desenvolver mecanismos com base no pensamento estratégico baseado em recursos e capacidades, no desenvolvimento de artefatos para gestão de contextos capacitadores direcionados para impulsionar o conhecimento organizacional e podem valorizar os excedentes cognitivos. Ou seja, valorizar o tempo que a empresa dispõe para desenvolvimento de atividades extra trabalho, motivando ações voluntárias, criando projetos para incentivo de inovação e empreendedorismo (Rezende et al.; 2016; Gohil; Deshpande, 2014).

De acordo com Ursacescu e Cioc (2016), a entropia informacional impacta diretamente em 4 quatro processos, os quais merecem atenção das organizações, conforme mostra o quadro 3, e quando identificado um nível de desorganização é provável que os níveis de entropia estejam elevados (Araújo et al., 2015).

\begin{tabular}{|c|c|}
\hline Processo & Descrição \\
\hline Processo de Gestão & $\begin{array}{c}\text { Conjunto de estruturas, funções e } \\
\text { relações estabelecidas com o objetivo de } \\
\text { tomada de decisão, baseado em recurso } \\
\text { de formação. }\end{array}$ \\
\hline $\begin{array}{c}\text { Processo de Ino- } \\
\text { vação }\end{array}$ & $\begin{array}{c}\text { Processo que permite a implementação } \\
\text { de novos bens, serviços e novas tecnolo- } \\
\text { gias, com base no acesso e exploração de } \\
\text { informação e conhecimento. }\end{array}$ \\
\hline $\begin{array}{c}\text { Processo de Comu- } \\
\text { nicação e Informa- } \\
\text { ção }\end{array}$ & $\begin{array}{c}\text { Tecnologias, práticas e infraestrutura que } \\
\text { permitem o processamento de dados } \\
\text { para os processos organizacionais. }\end{array}$ \\
\hline $\begin{array}{c}\text { Estratégia de Ne- } \\
\text { gócios }\end{array}$ & $\begin{array}{c}\text { Definição da direção estratégica, objeti- } \\
\text { vos e ações necessárias para alcançá-los. }\end{array}$ \\
\hline
\end{tabular}

Quadro 3. Processos organizacional expostos a entropia da informação

Fonte: Ursacescu; Cioc (2016)

As diferentes relações entre os diversos elementos que compôem o sistema organizacional podem oferecer somente pelas suas interações, grau moderado na produção de entropia e no fluxo de entropia negativa de entrada para sistemas abertos (Chang, 2013). Outro ponto a considerar é a complexidade das organizações, pois cada tipologia possui características únicas e um modelo de gestão que se aplica a uma, podendo não ser aplicável a outra, sem que seja antes avaliado o contexto de operação (Jing, 2011).

A colaboração da entropia negativa para o sistema de gestão está correlacionada à inclusão e exclusão de elementos dentro do sistema e às relações que ocorrem entre eles. Em muitas situações as organizações contratam profissionais, demitem profissionais, compram empresas e vendem empresas, ocorrem cisões ou formam conglomerados e a 
energia de uma soma-se a outra. Assim, eleva e diminiu a entropia, dependendo da situação, o que torna o papel dos líderes ainda mais desafiante (Quarati et al., 2016; Foster; Burkett, 2008).

\section{Liderança}

Quando perguntado sobre o perfil de liderança que os consultores identificam com maior frequência nas organizações, as Figuras 9,10 e 11 apresentam os resultados: 58\% informou que as lideranças estão focadas apenas nos resultados financeiros; 31\% considera o ambiente interno sua prioridade com pouca interface com ambiente externo; $8 \%$ ignoram o contexto organizacional em suas tomadas de decisões e apenas $4 \%$ possuem perfil para gerenciamento de conflitos.

Para Q3, $M p=6.7$ e nível de entropia que chega a $20.2 \%$ e Q4, $M p=6.0$ e nível de entropia $=18 \%$, demonstrando que a liderança necessita mudar o foco da gestão, pois está próximo de níveis significativos de entropia (Quadro 4).

Conforme Lee (2010), muitos líderes possuem baixa entropia. Esse fato pode contribuir para seu processo de gestão e que valores pessoais como senso de justiça, capacidade de ouvir, trabalho em equipe, que cria um ambiente organizacional inclusivo, são capazes de reduzir a entropia organizacional. Ainda, a autora reforça que a confiança nas tomadas de decisões e capacidade de comunicar e criar relacionamentos são primordiais para criação de cultura organizacional e gerar valor para o negócio. Como sugerido por Barrett (2010b), as lideranças possuem sete níveis de consciência, conforme demonstrado no quadro 5.

Perfil das lideranças

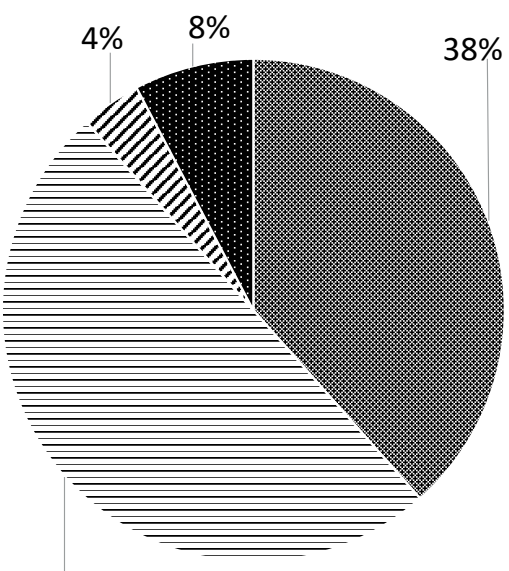

$50 \%$ $\begin{array}{ll}\text { Foco no ambiente } & \begin{array}{l}\text { Gerencia conflitos e } \\ \text { interno }\end{array} \\ =\begin{array}{l}\text { constrói relacionamentos } \\ \text { Foco nos resultados }\end{array} & \text { Ignora contexto organizacional } \\ \text { finceiros } & \text { nas decisões }\end{array}$

Figura 9. Perfil das lideranças apontados na pesquisa Fonte: elaborada pelos autores (2020).

\begin{tabular}{|c|c|c|c|c|c|c|c|c|c|c|c|c|c|c|}
\hline \multirow[t]{2}{*}{ Questão } & \multicolumn{2}{|c|}{$\begin{array}{l}\text { Servo-líder e } \\
\text { visionário - Age } \\
\text { com humilda- } \\
\text { de e compai- } \\
\text { xão }\end{array}$} & \multicolumn{2}{|c|}{\begin{tabular}{|c|} 
Gerencia \\
facilmente con- \\
flitos e investe \\
na construção \\
de relaciona- \\
mentos \\
\end{tabular}} & \multicolumn{2}{|c|}{$\begin{array}{c}\text { Considera o am- } \\
\text { biente interno sua } \\
\text { prioridade com } \\
\text { pouca interface } \\
\text { com ambiente } \\
\text { externo }\end{array}$} & \multicolumn{2}{|c|}{$\begin{array}{l}\text { Não considera } \\
\text { o contexto } \\
\text { organizacional } \\
\text { nas tomadas } \\
\text { de decisões }\end{array}$} & \multicolumn{2}{|c|}{$\begin{array}{l}\text { Focado apenas } \\
\text { nos resultados } \\
\text { financeiros }\end{array}$} & \multirow[t]{2}{*}{$\begin{array}{c}M p= \\
\sum w i x i / \\
\sum w i\end{array}$} & \multirow[t]{2}{*}{$\sum$ WiXi } & \multirow[t]{2}{*}{ Nqo } & \multirow[t]{2}{*}{$\begin{array}{l}\text { Score } \\
\% \text { NEo }\end{array}$} \\
\hline & $\mathrm{Xi}$ & Wi & $\mathrm{Xi}$ & Wi & $\mathrm{Xi}$ & $\mathrm{Wi}$ & $\mathrm{Xi}$ & Wi & $\mathrm{Xi}$ & $\mathrm{Wi}$ & & & & \\
\hline Q3 & 0 & 1 & 1 & 2 & 12 & 3 & 2 & 4 & 11 & 5 & 6,7 & 101,0 & 5,0 & 20,2 \\
\hline \multirow{3}{*}{ Cálculo } & \multicolumn{14}{|c|}{$M p=\sum$ wixi $/ \sum$ wi $=((1 * 0)+(2 * 1)+(3 * 12)+(4 * 2)+(5 * 11)) / 15=6,7$} \\
\hline & \multicolumn{14}{|c|}{$\sum \mathrm{WiXi}=((1 * 0)+(2 * 1)+(3 * 12)+(4 * 2)+(5 * 11))=101,0$} \\
\hline & \multicolumn{14}{|c|}{ Score $\%$ NEo $=\left(\sum \mathrm{WiXi} / 100\right) / \mathrm{Nqo}=(101 / 100) / 5=0,202=20,2 \%$} \\
\hline \multirow[t]{2}{*}{ Questão } & $\begin{array}{c}\text { Ex- } \\
\text { traor- } \\
\text { dinária }\end{array}$ & & Alta & & $\begin{array}{l}\text { Inter- } \\
\text { mediá- } \\
\text { ria }\end{array}$ & & Baixa & & $\begin{array}{c}\text { Inci- } \\
\text { piente }\end{array}$ & & $\begin{array}{c}M p= \\
\sum \text { wixi / } \\
\sum \text { wi }\end{array}$ & $\sum$ WiXi & Nqo & $\begin{array}{l}\text { Score } \\
\% \text { NEo }\end{array}$ \\
\hline & $\mathrm{Xi}$ & Wi & $\mathrm{Xi}$ & $\mathrm{Wi}$ & $\mathrm{Xi}$ & $\mathrm{Wi}$ & $\mathrm{Xi}$ & $\mathrm{Wi}$ & $\mathrm{Xi}$ & Wi & & & & \\
\hline Q4 & 0 & 1 & 1 & 2 & 12 & 3 & 13 & 4 & 0 & 5 & 6,0 & 90,0 & 5,0 & 18 \\
\hline \multirow{3}{*}{ Cálculo } & \multicolumn{14}{|c|}{$M p=\sum$ wixi $/ \sum$ wi $=\left(\left(1^{*} 0\right)+(2 * 1)+(3 * 12)+(4 * 13)+(5 * 0)\right) / 15=6,0$} \\
\hline & \multicolumn{14}{|c|}{$\Sigma \mathrm{WiXi}=(1 * 0)+(2 * 1)+(3 * 12)+(4 * 13)+\left(5^{*} 0\right)=90,0$} \\
\hline & \multicolumn{14}{|c|}{ Score $\% \mathrm{NEo}=\left(\sum \mathrm{WiXi} / 100\right) / \mathrm{Nqo}=(101 / 100) / 5=0,180=18 \%$} \\
\hline
\end{tabular}

Quadro 4. Estratificação seção 2 Liderança - Questões Q3 e Q4

Fonte: elaborado pelos autores (2020). 
Capacidade de comunicação das lideranças

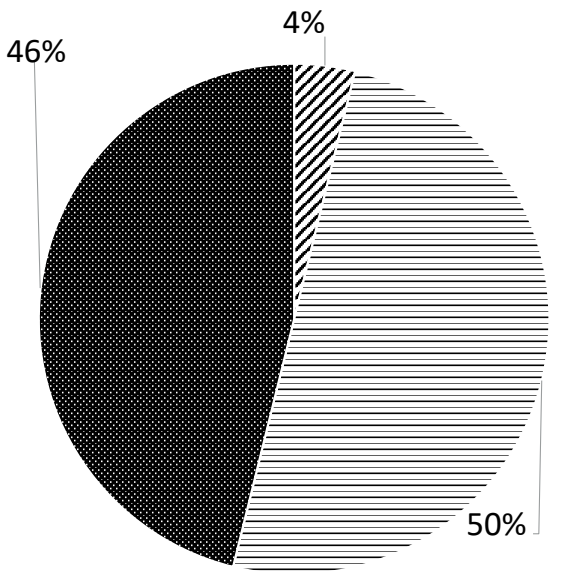

-Alta = Baixa $\quad \mathbf{x}$ Intermediária

Figura 10. Capacidade de comunicação das lideranças Fonte: elaborada pelos autores (2020).

\begin{tabular}{|c|c|c|}
\hline \multicolumn{2}{|c|}{$\begin{array}{l}\text { Nível de } \\
\text { consciência da } \\
\text { liderança }\end{array}$} & Características \\
\hline 7 & Servidão & $\begin{array}{l}\text { Líder visionário: serviço à sociedade, à } \\
\text { humanidade e ao planeta. Foco na ética, } \\
\text { responsabilidade social, sustentabilidade e } \\
\text { gerações futuras. Exibe sabedoria, compai- } \\
\text { xão e humildade. }\end{array}$ \\
\hline 6 & $\begin{array}{l}\text { Faz a dife- } \\
\text { rença }\end{array}$ & $\begin{array}{l}\text { Mentor / Líder de Parceiro: Alianças e par- } \\
\text { cerias estratégicas, liderança de servidores. } \\
\text { Concentre-se na satisfação dos funcionários, } \\
\text { mentoria e coaching. Exibe empatia e utiliza } \\
\text { a intuição na tomada de decisões. }\end{array}$ \\
\hline 5 & $\begin{array}{l}\text { Coesão } \\
\text { interna }\end{array}$ & $\begin{array}{l}\text { Líder Inspirador: Forte cultura coesiva e ca- } \\
\text { pacidade de ação coletiva. Concentre-se na } \\
\text { visão, missão e valores. Exibe autenticidade, } \\
\text { integridade, paixão e criatividade. }\end{array}$ \\
\hline 4 & $\begin{array}{l}\text { Transfor- } \\
\text { mação }\end{array}$ & $\begin{array}{l}\text { Facilitador / Influenciador: Empoderamen- } \\
\text { to, adaptabilidade e aprendizado contínuo. } \\
\text { Foco no crescimento pessoal, trabalho em } \\
\text { equipe e inovação. Exibe coragem, responsa- } \\
\text { bilidade, iniciativa e responsabilidade. }\end{array}$ \\
\hline 3 & Autoestima & $\begin{array}{c}\text { Gerente de desempenho: sistemas e proces- } \\
\text { sos de alto desempenho. Foco em estraté- } \\
\text { gia, desempenho, excelência, qualidade, } \\
\text { produtividade e eficiência. Exibe orgulho no } \\
\text { desempenho. }\end{array}$ \\
\hline 2 & $\begin{array}{l}\text { Relaciona- } \\
\text { mento }\end{array}$ & $\begin{array}{l}\text { Gerente de Relacionamento: reconhecimen- } \\
\text { to de funcionários, comunicação aberta e } \\
\text { resolução de conflitos. Cria a lealdade de } \\
\text { funcionários e clientes e trata as pessoas } \\
\text { com dignidade. }\end{array}$ \\
\hline
\end{tabular}

\begin{tabular}{|c|c|c|}
\hline 1 & $\begin{array}{c}\text { Sobrevi- } \\
\text { vência }\end{array}$ & $\begin{array}{c}\text { Gerente de crise: estabilidade financei- } \\
\text { ra, crescimento organizacional e saúde e } \\
\text { segurança dos funcionários. Mostra calma } \\
\text { em face do caos e determinação no meio do } \\
\text { perigo. }\end{array}$ \\
\hline
\end{tabular}

Quadro 5. Níveis de consciência da liderança e suas características Fonte: elaborado pelos autores (2020), com base em Barrett (2010b).

Os líderes que se enquadram no nível 1 estão, em geral, preocupados com o retorno financeiro e possuem alta capacidade de gerir orçamentos, cuidam da saúde e segurança de seus colaboradores, sabem lidar com situações complexas de curto e longo prazo e se preocupam com o nível de conformidade de sua gestão em cumprir regulamentos e procedimentos. Outro ponto positivo é a capacidade de lidar com crises e a sobrevivência financeira da organização. Os líderes que possuem um perfil de sobrevivência têm medo de delegar e confiar nas pessoas, sendo muitas vezes sabotados pelo seu próprio estilo de liderar. São gananciosos, solitários e isso não contribui para uma gestão eficiente, gerando alta entropia.

A liderança de relacionamento trata-se de um perfil manipulador, possui baixa capacidade de comunicação e não evitam conflitos. Exigem obediência em troca de benefícios pessoais e são geralmente paternalistas. Não confiam em seu time e duvidam da capacidade das pessoas. Segundo Barrett (2010b), esse perfil ocupa cargo de liderança geralmente em empresas familiares. Isso poderia explicar a razão dos respondentes avaliarem a capacidade de comunicação das lideranças como sendo: $96 \%$ consideram "baixa ou intermediária" e apenas $4 \%$ concordam que as lideranças têm alta capacidade de comunicação.

\section{Estratégia}

$\mathrm{Na}$ figura 11, que trata da estratégia organizacional, Q5, $\mathrm{Mp}=4.3$ demonstra estar no caminho certo na busca da baixa entropia. Ainda o score de $13 \%$ no nível de entropia, evidencia que necessita um esforço em alinhar as estratégias direcionadas para o ataque à concorrência com as demais partes interessadas, como colaboradores e sociedade, ainda que esteja no nível de baixa entropia.

Para Q5 (figura 11 e quadro 6), $M p=5,6$ e score de entropia $15.8 \%$, significa um nível significativo de entropia e remete à demanda de melhoria da comunicação com as partes interessadas, permitindo a elas conhecer a empresa e seu propósito. 
Nível de influência das partes interessadas sobre a definição da estratégia

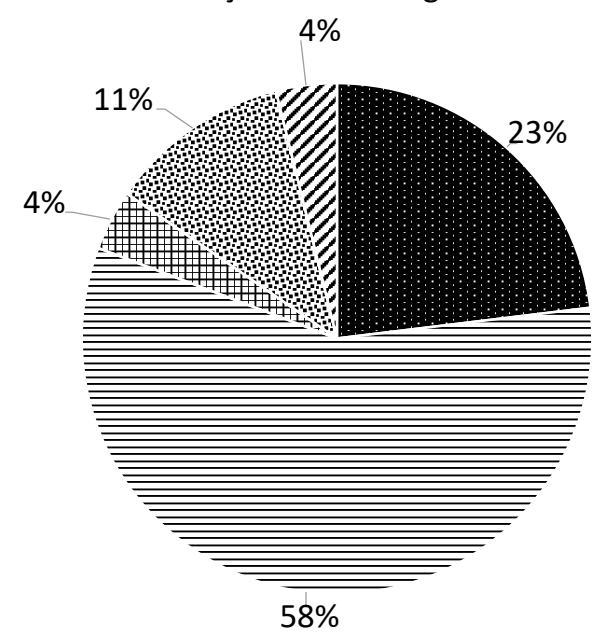

\section{RColaboradores :aciedade \\ - Concorrência \& Sociedade, Colaboradores \\ ҒGovernos}

Figura 11. Nível de influência das partes interessadas sobre a definição da estratégia

Fonte: elaborada pelos autores (2020).

No entendimento dos consultores, $58 \%$ das empresas sofre maior influência da concorrência quando da definição de sua estratégia e $23 \%$ são influenciadas pelos colaboradores.

Sob a ótica da entropia em estratégia e gestão, as organizações necessitam de engajamento de suas lideranças para definir uma estratégia coerente com suas interfaces exógenas. Ao definir uma estratégia que não leve em conta, as possíveis interpretações dos anseios de todos os envolvidos, a capacidade de julgamento diante da complexidade do am- biente de decisão fica prejudicada ou limita-se a uma abordagem rasa, quando deveria ser profunda e abrangente, pois as informações e dados relevantes que podem indicar fragilidades podem estar em todos os níveis da organização (Ceptureanu et al., 2017; Bruyn, 2014).

Ao considerar a prioridade dada pelas organizações aos riscos e oportunidades nas tomadas de decisões (Figura $12 \mathrm{e}$ questão 6), 42\% dos respondentes afirmam que as organizações não estão preparadas para contemplá-los. Ainda, 27\% consideram média e $27 \%$ entendem que consideram alta prioridade, sendo que neste último caso está mais focado nas grandes corporações e $4 \%$ não consideram.

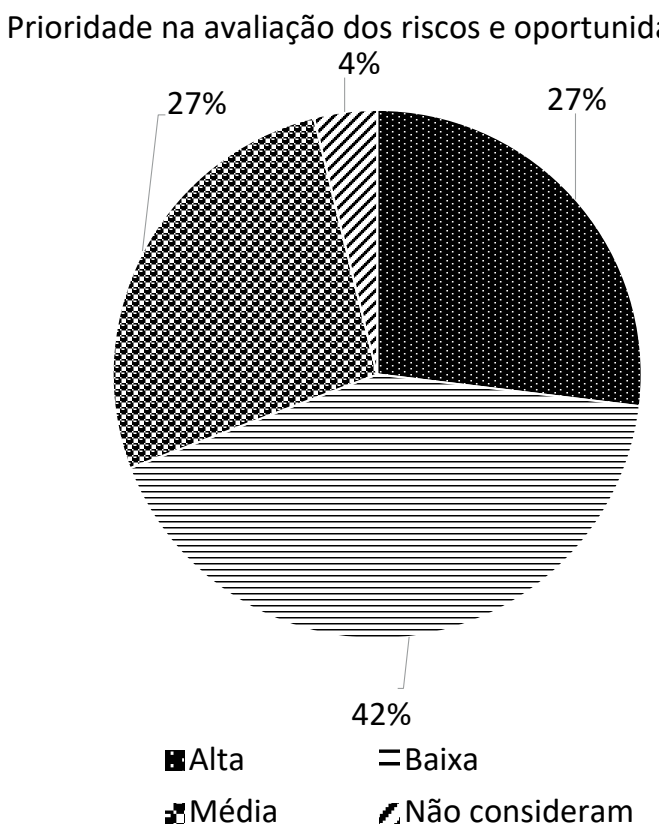

Figura 12. Prioridade dada aos riscos e oportunidades Fonte: elaborada pelos autores (2020).

\begin{tabular}{|c|c|c|c|c|c|c|c|c|c|c|c|c|c|c|}
\hline \multirow[t]{2}{*}{ Questão } & \multicolumn{2}{|c|}{ Sociedade } & \multicolumn{2}{|c|}{ Colaboradores } & \multicolumn{2}{|c|}{ Concorrência } & \multicolumn{2}{|c|}{ Governos } & \multicolumn{2}{|c|}{ ONGs } & \multirow[t]{2}{*}{$\begin{array}{c}M p=\sum w i x i \\
/ \sum w i\end{array}$} & \multirow[t]{2}{*}{$\Sigma$ WiXi } & \multirow[t]{2}{*}{ Nqo } & \multirow[t]{2}{*}{$\begin{array}{l}\text { Score } \\
\% \text { NEo }\end{array}$} \\
\hline & $\mathrm{Xi}$ & Wi & $\mathrm{Xi}$ & $\mathrm{Wi}$ & $\mathrm{Xi}$ & Wi & $\mathrm{Xi}$ & Wi & $\mathrm{Xi}$ & $\mathrm{Wi}$ & & & & \\
\hline Q5 & 4 & 1 & 6 & 2 & 15 & 3 & 1 & 4 & 0 & 5 & 4,3 & 65,0 & 5,0 & 13 \\
\hline \multirow{3}{*}{ Cálculo } & \multicolumn{14}{|c|}{$\mathrm{Mp}=\sum$ wixi $/ \sum \mathrm{wi}=((1 * 4)+(2 * 6)+(3 * 15)+(4 * 1)+(5 * 0)) / 15=4,3$} \\
\hline & \multicolumn{14}{|c|}{$\sum \mathrm{WiXi}=(1 * 4)+(2 * 6)+(3 * 15)+(4 * 1)+(5 * 0)=65,0$} \\
\hline & \multicolumn{14}{|c|}{ Score $\% \mathrm{NEo}=\left(\sum \mathrm{WiXi} / 100\right) / \mathrm{Nqo}=(65 / 100) / 5=0,13=13 \%$} \\
\hline \multirow[t]{2}{*}{ Questão } & \multicolumn{2}{|c|}{ Altíssima } & \multicolumn{2}{|c|}{ Alta } & \multicolumn{2}{|c|}{ Média } & \multicolumn{2}{|c|}{ Baixa } & \multicolumn{2}{|c|}{$\begin{array}{c}\text { Não conside- } \\
\text { ram }\end{array}$} & $\begin{array}{c}M p=\sum w i x i \\
/ \sum w i\end{array}$ & $\Sigma W_{i X i}$ & Nqo & $\begin{array}{l}\text { Score } \\
\% \text { NEo }\end{array}$ \\
\hline & $\mathrm{Xi}$ & $\mathrm{Wi}$ & $\mathrm{Xi}$ & Wi & $\mathrm{Xi}$ & Wi & $\mathrm{Xi}$ & Wi & $\mathrm{Xi}$ & Wi & & & & \\
\hline Q6 & 0 & 1 & 7 & 2 & 7 & 3 & 11 & 4 & 1 & 5 & 5,6 & 79,1 & 5,0 & 15,8 \\
\hline \multirow[b]{2}{*}{ Cálculo } & \multicolumn{14}{|c|}{$M p=\sum$ wixi $/ \sum$ wi $=((1 * 0)+(2 * 1)+(3 * 12)+(4 * 13)+(5 * 0)) / 15=6,0$} \\
\hline & \multicolumn{14}{|c|}{$\sum \mathrm{WiXi}=(1 * 4)+(2 * 6)+(3 * 15)+(4 * 1)+(5 * 0)=79,1$} \\
\hline
\end{tabular}

Quadro 6. Estratificação seção Estratégia - Questões Q5 e Q6 Fonte: elaborado pelos autores (2020) 
A definição da estratégia organizacional deve ser pensada e estruturada com base na densidade de energia circundante à organização. Tudo que acontence à sua volta poderá interferir na execução dessa estratégia, impondo uma variação correspondente nos sistemas econômicos, assim como ocorre nos sistemas naturais (Annila; Salthe, 2009). 0 ambiente da organização é o conjunto de todos os fatores ou forças que atuam sobre ela, que podem impactar o desempenho da organização ou ser impactado por ela (Chun et al., 2013).

A valorização dos resultados financeiros pelas lideranças organizacionais é sem dúvida, segundo Kümmel (2016), o que motiva a existência das organizações. No entanto, não se pode admitir que no século XXI seja somente essa, pois nenhum empreendimento sobreviverá sem considerar demais elementos que perfazem a existência de um negócio. Assim, devem ter em mente o princípio da sustentabilidade ao definir suas estratégias.

\section{Cultura Organizacional}

A diversidade (Figura 13) nas organizações é impulsionada por diversos fatores, segundo os respondentes: $38 \%$ consideram que as empresas promovem investimentos em diversidade devido a exigências legais, $31 \%$ por pressão da sociedade civil, $23 \%$ para melhoria da imagem frente a seus clientes e consumidores e apenas $8 \%$ consideram investir em diversidade, seja cultural, de gênero, social ou de qualquer natureza como sendo um diferencial competitivo.

\section{Motivação para investimentos em diversidade}

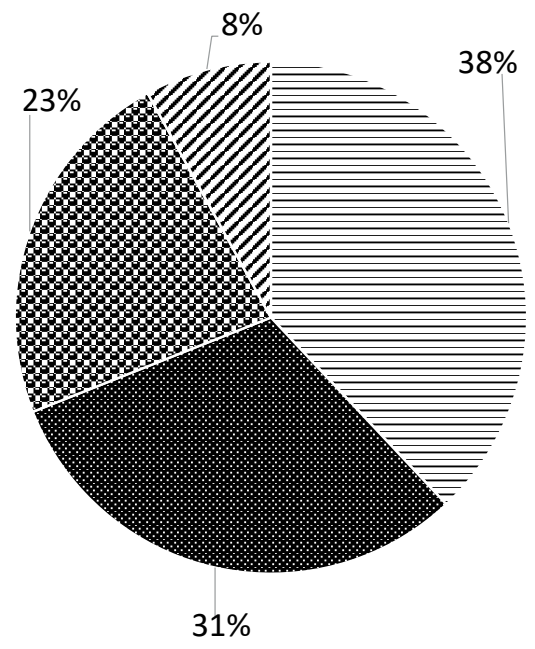

$$
\begin{array}{ll}
\text { =Exigência Legal } & \mathbf{x} \text { Melhoria da Imagem } \\
\mathbf{8} \text { Pressão da Sociedade } & \text { /Deferencial Competitivo }
\end{array}
$$

Figura 13. Motivação para investimentos e diversidade corporativa Fonte: elaborada pelos autores (2020).
A cultura organizacional é um elemento intangível e se trasnforma ao longo do tempo, sofrendo influência de fatores, muitas vezes desconhecidos das empresas. A organização é um sistema dinâmico, vivo e precisa considerar esse fato dentro da gestão. Se ocorre transformação em uma variável dentro do sistema, todo sistema sofrerá menos ou mais o impacto desse evento (Rãdulescu, 2013).

Ao promover ações para transformar a cultura organizacional, as lideranças precisam entender o erros do passado, avaliar o que não está dando certo e somente após uma análise criteriosa deve-se promover novas mudanças. Barrett (2010a) salienta que três fatores prejudicam uma gestão para mudança da cultura: 1 . focar apenas no alinhamento pessoal, 2. atenção apenas na coesão dos grupos e 3. falha ao personalizar os programas de transformação.

Alguns elementos precisam ser considerados pelas organizações para fortalecer sua cultura e podem ser enumerados em etapas conforme descrito no quadro 7 .

Os profissionais que atuam na posição de gerentes não podem esquecer o papel que representam dentro das organizações. Eles devem manter-se em padrões mais elevados quando se trata de pessoas. Na concepção de Prahalad (2010), as pessoas buscam justiça, não favores. Desejam alguém que os ouçam, que se importem, que valorize a importância da lealdade à organização, profissão, comunidade, sociedade e, acima de tudo, família.

Ações direcionadas para programas de responsabilidade socioambientais podem refletir numa maior integração entre a empresa, seus colaboradores e sociedade, bem como melhorar a imagem da empresa. Ao mesmo tempo, pode elevar o nível de comprometimento com os valores organizacionais e a cultura da organização, pois de acordo com o quadro 8 , o nível de $Q 7=8.2$ e entropia acima de $24.6 \%$, alcança um nível sério de entropia (21\%-30\%), colocando a organização em alto risco para tomadas de decisões que podem gerar perdas de capital humano e financeiro.

No que se refere a $Q 8, M p=5.9$, indica que está mais próximo de alcançar um nível de equilíbrio. No entanto, aprimorar a interface entre o ambiente interno e externo é necessário. A entropia de $17.8 \%$ reforça o tamanho do esforço a ser desprendido na busca de uma comunicação mais assertiva.

$\mathrm{Na}$ avaliação dos consultores, o nível de conscientização das partes interessadas (Figura 14), no que se refere ao contexto organizacional, os objetivos e as metas definidas. Apenas $11 \%$ dos respondentes concordam que as partes interessadas têm conhecimento satisfatório sobre a organização tanto internamente como externamente e os demais $89 \%$, que este nível está entre o nível baixo e médio. 


\begin{tabular}{|c|c|c|}
\hline \multicolumn{2}{|r|}{ Etapas } & \multirow[b]{2}{*}{$\begin{array}{l}\text { Descrição } \\
\text { O processo de mudança total do sistema começa com o compromisso pessoal do líder e da equipe de liderança para } \\
\text { sua própria transformação pessoal. Isso é necessário porque a cultura da organização é um reflexo da consciência } \\
\text { de liderança. Uma iniciativa de mudança cultural deve ser possuída e supervisionada pessoalmente pelo líder de } \\
\text { uma organização e totalmente apoiada pela equipe de liderança. A transformação cultural não é algo que pode ser } \\
\text { delegado: nem pode ser entregue a uma equipe externa de consultores. É algo que a organização tem que fazer por } \\
\text { si mesma, e é sempre em andamento: não é um projeto, é um processo! É importante que o líder seja ciente de que } \\
\text { isso pode acontecer e está disposto a ir em frente para o bem da empresa. }\end{array}$} \\
\hline 1 & $\begin{array}{l}\text { Compro- } \\
\text { misso da } \\
\text { liderança }\end{array}$ & \\
\hline 2 & $\begin{array}{l}\text { Medição } \\
\text { de linha } \\
\text { de base }\end{array}$ & $\begin{array}{c}\text { Depois que o líder e a equipe de liderança se comprometerem com o processo, deve-se realizar uma avaliação dos } \\
\text { valores culturais de toda a organização e, ao mesmo tempo construir um scorecard de níveis atuais de desempenho } \\
\text { da organização, engajamento dos funcionários, satisfação do cliente, entropia cultural, alinhamento de valores, etc. A } \\
\text { ideia é desenvolver um conjunto de medições de linha de base a partir do qual se pode medir o progresso da trans- } \\
\text { formação cultural. }\end{array}$ \\
\hline 3 & $\begin{array}{l}\text { Visão e } \\
\text { Missão }\end{array}$ & $\begin{array}{l}\text { Depois de concluir as medições de linha de base, o próximo passo é definir aonde a empresa está indo e como vai } \\
\text { chegar lá. É hora de desenvolver uma visão interna e externa e missão para a organização. Se a organização já tem } \\
\text { uma visão e missão, será importante revisitá-la, especialmente se houver novas pessoas na equipe de liderança. } \\
\text { Definir a visão é o trabalho da equipe de liderança. Esta tarefa não pode ser delegada. Todos devem participar e suas } \\
\text { contribuições e comentários, uma vez que a equipe de liderança esteja confortável com a visão de declarações que } \\
\text { eles produziram a mesma deve ser validada e comunicada. }\end{array}$ \\
\hline 4 & $\begin{array}{c}\text { Valores e } \\
\text { comporta- } \\
\text { mentos }\end{array}$ & $\begin{array}{l}\text { Como parte do processo de desenvolvimento de uma visão e missão para a organização, também é importante de- } \\
\text { finir os valores e comportamentos da organização. Os resultados da avaliação de valores culturais serão úteis nesse } \\
\text { sentido. Na medida do possível, todos os funcionários devem estar envolvidos nesse processo. } \\
\text { Os valores devem: possuir palavras únicas ou pequenas frases que são facilmente memoráveis; apoiar a visão e mis- } \\
\text { são; incluir valores de relacionamento, bem como valores organizacionais - ou seja, confiança e melhoria contínua. }\end{array}$ \\
\hline 5 & $\begin{array}{l}\text { Razões } \\
\text { convin- } \\
\text { centes } \\
\text { para a mu- } \\
\quad \text { dança }\end{array}$ & $\begin{array}{l}\text { Deve haver um claro entendimento entre o nível executivo sobre o motivo pelo qual a organização está embarcando } \\
\text { em todo um processo de mudança de sistema. O processo de mudança deve ser fundamentado na realidade, e im- } \\
\text { pulsionada pelo otimismo realista que fornece a população de funcionários e executivos com esperança de sucesso. } \\
\text { Em empresas que sofrem com baixo desempenho, as razões devem ser convincentes para a mudança. Para empre- } \\
\text { sas de alto desempenho, as razões para mudança devem se concentrar três fatores: como a empresa pode permane- } \\
\text { cer adaptável; posicionando-se para o futuro; e construir sua resiliência de longo prazo. }\end{array}$ \\
\hline 6 & $\begin{array}{l}\text { Alinha- } \\
\text { mento } \\
\text { pessoal }\end{array}$ & $\begin{array}{c}\text { O alinhamento pessoal deve começar com a equipe de liderança. Para este fim, será importante para todos os } \\
\text { membros da equipe de liderança e se concentrar em seu próprio domínio pessoal, buscando feedback e, se necessá- } \\
\text { rio, receber coaching (aconselhamento).Uma vez que a equipe de liderança embarcou em um processo de maestria } \\
\text { pessoal para melhorar sua inteligência emocional deve dividir o conhecimento adquirido com demais membros das } \\
\text { equipes. }\end{array}$ \\
\hline 7 & $\begin{array}{l}\text { Alinha- } \\
\text { mento } \\
\text { estrutural }\end{array}$ & $\begin{array}{c}\text { O objetivo do programa de alinhamento estrutural é reconfigurar as estruturas, sistemas, processos, políticas, } \\
\text { incentivos e procedimentos para que reflitam visão, missão, valores e comportamentos desejados da organização, } \\
\text { institucionalizando-os na cultura da organização. Em grandes organizações, o alinhamento estrutural pode levar de } 2 \\
\text { a } 3 \text { anos para ser implementado. A responsabilidade por isso geralmente recai sobre a função de Recursos Humanos. } \\
\text { Este passo é um que é mais frequentemente esquecido em iniciativas de transformação cultural. }\end{array}$ \\
\hline 8 & $\begin{array}{c}\text { Alinha- } \\
\text { mento de } \\
\text { valores }\end{array}$ & $\begin{array}{l}\text { A finalidade do programa de alinhamento de valores é inculcar os valores adotados e comportamentos da organiza- } \\
\text { ção na população de executivos e funcionários. A partir do conteúdo informativo, o programa deve dar aos partici- } \\
\text { pantes oportunidade de explorar seus próprios valores e compreender e praticar o conceito de tomada de decisão } \\
\text { baseada em valores. Por exemplo, se valorizamos a confiança, então tomamos decisões que nos permitem exibir } \\
\text { confiança. Se valorizamos a responsabilidade, então tomamos decisões que nos permitem exibir a responsabilidade. }\end{array}$ \\
\hline 9 & $\begin{array}{l}\text { Alinha- } \\
\text { mento da } \\
\text { missão }\end{array}$ & $\begin{array}{l}\text { O objetivo do programa de alinhamento da missão é divulgar a visão e a missão da organização para a população } \\
\text { executiva e de funcionários. Apesar de conteúdo informativo, o programa deve dar aos participantes a oportunidade } \\
\text { de explorar o seu próprio sentido de missão e visão, e ver como o seu papel apoia a visão ou missão da organização. } \\
\text { É muito importante que todos na organização tenham uma linha clara de visão entre o trabalho que fazem a cada } \\
\text { dia e a visão e / ou missão da organização. Sem uma linha de visão clara, as pessoas não são capazes de valorizar sua } \\
\text { contribuição e entender como eles fazem a diferença. }\end{array}$ \\
\hline
\end{tabular}

Quadro 7. Níveis de consciência de liderança e suas características

Fonte: elaborado pelos autores (2020) com base em Barrett (2010a). 


\begin{tabular}{|c|c|c|c|c|c|c|c|c|c|c|c|c|c|c|}
\hline Questão & \multicolumn{2}{|c|}{$\begin{array}{c}\text { Geração de } \\
\text { valor }\end{array}$} & \multicolumn{2}{|c|}{$\begin{array}{c}\text { Diferencial } \\
\text { competitivo }\end{array}$} & \multicolumn{2}{|c|}{$\begin{array}{l}\text { Melhorar } \\
\text { imagem }\end{array}$} & \multicolumn{2}{|c|}{$\begin{array}{l}\text { Pressão da } \\
\text { Sociedade }\end{array}$} & \multicolumn{2}{|c|}{ Exigência legal } & $\begin{array}{c}M p=\sum w i x i \\
/ \sum w i\end{array}$ & $\sum$ WiXi & Nqo & $\begin{array}{l}\text { Score } \\
\% \text { NEo }\end{array}$ \\
\hline \multirow{2}{*}{ Q7 } & $\mathrm{Xi}$ & Wi & $\mathrm{Xi}$ & Wi & $\mathrm{Xi}$ & Wi & $\mathrm{Xi}$ & Wi & $\mathrm{Xi}$ & Wi & & & & \\
\hline & 0 & 1 & 2 & 2 & 11 & 3 & 9 & 4 & 10 & 5 & 8,2 & 123,0 & 5,0 & 24,6 \\
\hline \multirow{3}{*}{ Cálculo } & \multicolumn{14}{|c|}{$\mathrm{Mp}=\sum \mathrm{wixi} / \sum \mathrm{wi}=((1 * 0)+(2 * 2)+(3 * 11)+(4 * 9)+(5 * 10)) / 15=8,2$} \\
\hline & \multicolumn{14}{|c|}{$\sum \mathrm{WiXi}=(1 * 0)+(2 * 2)+(3 * 11)+(4 * 9)+(5 * 10)=123,0$} \\
\hline & \multicolumn{14}{|c|}{ Score $\%$ NEo $=\left(\sum\right.$ WiXi $\left./ 100\right) / \mathrm{Nqo}=(123 / 100) / 5=0,246=24,6 \%$} \\
\hline Questão & \multicolumn{2}{|c|}{ Altíssima } & \multicolumn{2}{|c|}{ Alta } & \multicolumn{2}{|c|}{ Média } & \multicolumn{2}{|c|}{ Baixa } & \multicolumn{2}{|c|}{$\begin{array}{c}\text { Não conside- } \\
\text { ram }\end{array}$} & $\begin{array}{c}M p=\sum w i x i \\
/ \sum w i\end{array}$ & $\sum$ WiXi & $\mathrm{Nqo}$ & $\begin{array}{l}\text { Score } \\
\% \text { NEo } \\
\end{array}$ \\
\hline \multirow{2}{*}{ Q8 } & $\mathrm{Xi}$ & Wi & $\mathrm{Xi}$ & Wi & $\mathrm{Xi}$ & Wi & $\mathrm{Xi}$ & Wi & $\mathrm{Xi}$ & Wi & & & & \\
\hline & 0 & 1 & 3 & 2 & 9 & 3 & 14 & 4 & 0 & 5 & 5,9 & 89,0 & 5,0 & 17,8 \\
\hline \multirow{3}{*}{ Cálculo } & \multicolumn{14}{|c|}{$M p=\sum$ wixi $/ \sum$ wi $=((1 * 0)+(2 * 3)+(3 * 9)+(4 * 14)+(5 * 0)) / 15=5,9$} \\
\hline & \multicolumn{14}{|c|}{$\Sigma \mathrm{WiXi}=(1 * 0)+(2 * 3)+(3 * 9)+(4 * 14)+(5 * 0)=89,0$} \\
\hline & \multicolumn{14}{|c|}{ Score $\%$ NEo $=(\Sigma \mathrm{WiXi} / 100) / \mathrm{Nqo}=(89 / 100) / 5=0,178=17,8 \%$} \\
\hline
\end{tabular}

Quadro 8. Estratificação seção Cultura Organizacional - Q7 e Q8

Fonte: elaborado pelos autores (2020).

Nível de conhecimento
das partes interessadas sobre as organizações

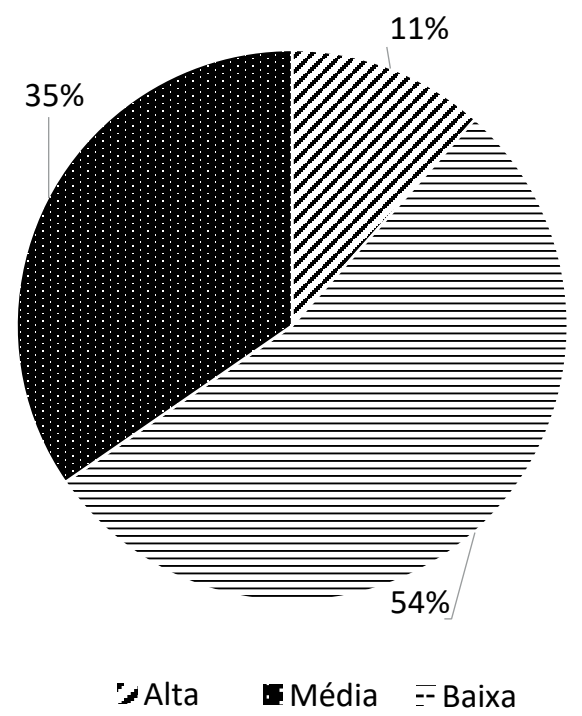

Figura 14. Nível de conhecimento das partes interessadas sobre as organizações

Fonte: elaborada pelos autores (2020).

Consoante com Ceptureanu et al. (2017), uma organização sem uma visão sistêmica não alcançará o empreendedorismo corporativo, pois segundo os autores, o início de tudo é o conhecimento de seu ambiente de atuação, e por conseguinte uma abordagem consistente das partes envolvidas em sua cadeia de valor e não poderá sob nenhuma hipótese ignorar as variáveis de caráter econômico, gerencial, demográfico, cultural, científico, psico-sociológico, educacional, que também inlcuem os elementos de importância ecológica, política e legal, que constituem sua essência organizacional.
A estrutura organizacional formada pelos seus elementos tangíveis e intangíveis permanecerá inalterado até que o aumento de entropia altere suas configurações, ou seja, a desordem. A influência que a entropia exerce sobre a organização gerará instabilidade crítica, podendo levar a fragmentação do sistema. No entanto, tudo pode ser corrigido em tempo, quando existe monitoramento e medições adequadas do desempenho do sistema, impedindo que se chegue a uma situação em que a sobrevivência da organização seja colocada em risco (Stephen; Dixon, 2009).

A entropia organizacional pode irromper afetando sua cultura quando mudanças abruptas nos níveis hierárquicos ocorrem. Quando a organização passa por um período de crise financeira gerada por fatores externos, como economia, políticas governametais, entre outros, algumas linhas de comando são movidas ou removidas, ou ainda ocorrem números exponenciais de demissões, levando a organização de maneira forçada a tomar medidas rígidas para o equilíbrio financeiro. Nesse momento, a entropia aumenta e ocorre muitas vezes o encerramento das atividades (Chappel; Dewey, 2015).

\section{Práticas Operacionais}

Sobre o nível alinhamento entre as práticas operacionais (Figura 15) e planejamento estratégico nas organizações, os consultores em sua grande maioria, sendo $65 \%$, concordam que as práticas organizacionais não refletem seu planejamento estratégico, havendo uma grande disparidade entre teoria e prática cotidiana. Segundo Hongkun et al. (2016), as práticas operacionais nas organizações evidenciam o grau de conscientização, a eficiência da comunicação e valorização da força de trabalho. A pesquisa também evidenciou que $65 \%$ dos consultores classificam como "péssimo ou ruim" o nível de valorização da participação dos colaborares nas soluções de problemas, 31\% entendem que seria "bom” e 4\% “ótimo" (Figura 16). 
Nível de alinhamento das práticas operacionais à estratégia

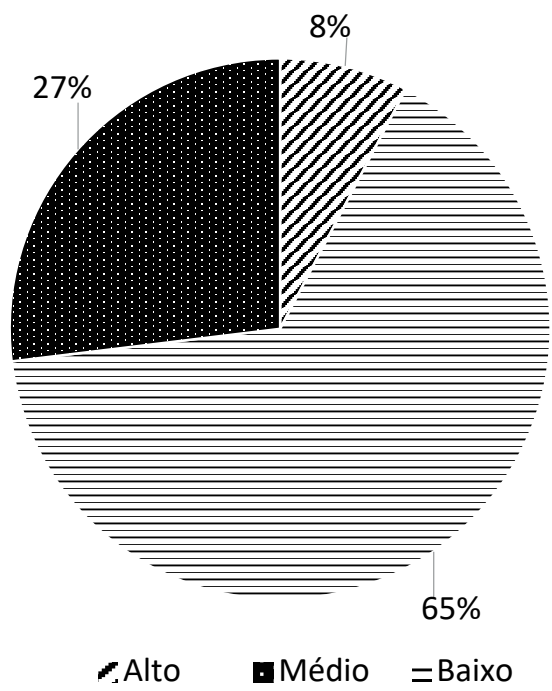

Figura15. Nível de alinhamento entre práticas operacionais e estratégia

Fonte: elaborada pelos autores (2020).

Nível de reconhecimento às contribuições dos trabalhadores

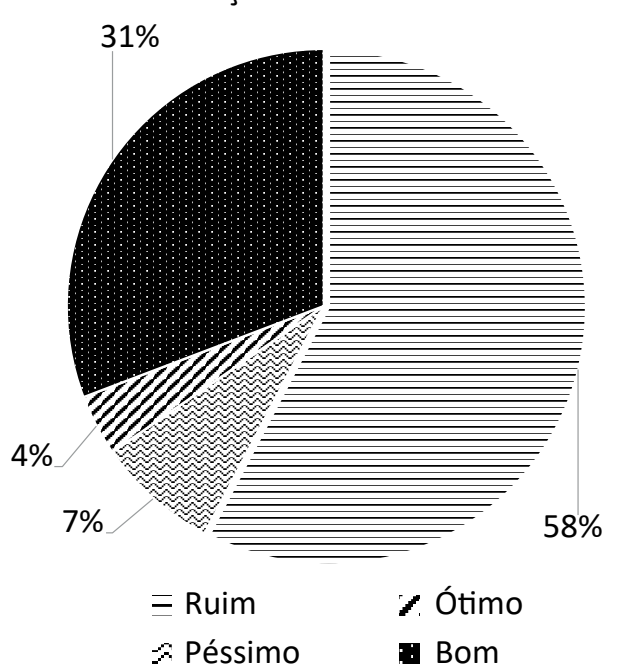

Figura 16. Nível de valorização dos colaboradores na solução dos problemas

Fonte: elaborada pelos autores (2020)

De acordo com Grecio (2016), ao aceitar o fato de que a conservação da energia é importante para manutenção dos sistemas em funcionamento e que a energia do universo é constante e transformada indefinidamente, uma analogia pode ser feita com a energia que os indivíduos desprendem nas práticas operacionais dentro das organizações.
$\mathrm{Na}$ medida que as práticas organizacionais não estão alinhadas com a estratégia definida como o caminho a seguir, passa a existir cada vez mais distância entre o onde a empresa deseja chegar e o que efetivamente acontece para sustentar sua missão. Assim, a energia disponível para gerir o negócio, não direcionada, faz com que mais energia seja empreendida e assim cria-se um ambiente propício à fragmentação pela pressão exercida sobre o sistema (Vasconcelos et al., 2015).

O quadro 9 apresenta os resultados que trata das práticas operacionais: Q9, Mp=6.2 e entropia 18.6\%; Q10, Mp=6.4 e entropia $19.2 \%$. Elas evidenciam que a organização está próxima ao nível de energia significativa. Isso significa que a estratégia organizacional está distante das práticas da organização. Nesse sentido, se faz necessária ação de alinhamento, através de treinamentos e desenvolvimento da força de trabalho.

Os fatores informação e comunicação deficiente também podem impactar diretamente sobre o desempenho organizacional, seja positivamente ou negativamente. O gap existente entre a filosofia da organização e como a força de trabalho a entende, precisam ser reavaliadas na prática. Pesquisas de clima organizacional podem indicar os fatores que estejam impactando e direcionando ações mais efetivas para corrigir os possíveis desvios (Almeida-Santos et al., 2014; Johnson et al., 2013).

Ao analisar as razões por que as pessoas trabalham em organizações, uma variedade de motivos pode surgir e possivelmente não estará resumido em apenas uma, mas em um conjunto delas. Para Mcauley et al. (2013), pode-se enumerar: recompensa econômica, satisfação individual, filiação a um grupo social, entre outras, o que vai variar de acordo com os valores individuais.

A pesquisa evidencia que as organizações precisam compreender sua força de trabalho e dar às pessoas um sentido de pertencimento à organização, e que para um negócio ter uma gestão eficaz é imprescindível que possua profissionais competentes suficiente para gerir pessoas e não apenas números, concentrando a devida atenção aos difrentes aspectos que elevam a moral e motivação dos colaboradores (Mcauley et al., 2013).

A desordem causada pela entropia leva a uma maior desordem e isso pode ser observado no valor atribuído ao reconhecimento dos colaboradores. Quanto maior a desorganização no sistema, menor será a chance de um líder reconhecer que seus colaboradores mereçam algum reconhecimento, já que sua participação na gestão se perde em meio a tanta turbulência, ainda que possa executar ações que poderiam representar valor para a organização (Ali et al., 2017; Bolisani; Bratianu, 2018). 


\begin{tabular}{|c|c|c|c|c|c|c|c|c|c|c|c|c|c|c|}
\hline \multirow[t]{2}{*}{ Questão } & \multicolumn{2}{|c|}{ Muito Alto } & \multicolumn{2}{|c|}{ Alto } & \multicolumn{2}{|c|}{ Moderado } & \multicolumn{2}{|c|}{ Baixo } & \multicolumn{2}{|c|}{$\begin{array}{l}\text { Nenhum ou } \\
\text { insignificante }\end{array}$} & \multirow[t]{2}{*}{$\begin{array}{c}M p=\sum \text { wixi } \\
/ \sum w i\end{array}$} & \multirow[t]{2}{*}{$\sum$ WiXi } & \multirow[t]{2}{*}{ Nqo } & \multirow[t]{2}{*}{$\begin{array}{l}\text { Score } \\
\% \text { NEo }\end{array}$} \\
\hline & $\mathrm{Xi}$ & $\mathrm{Wi}$ & $\mathrm{Xi}$ & Wi & $\mathrm{Xi}$ & Wi & $\mathrm{Xi}$ & $\mathrm{Wi}$ & $\mathrm{Xi}$ & $\mathrm{Wi}$ & & & & \\
\hline Q9 & 0 & 1 & 2 & 2 & 7 & 3 & 17 & 4 & 0 & 5 & 6,2 & 93,0 & 5,0 & 18,6 \\
\hline \multirow{3}{*}{ Cálculo } & \multicolumn{14}{|c|}{$\mathrm{Mp}=\sum$ wixi $/ \sum$ wi $=((1 * 0)+(2 * 2)+(3 * 7)+(4 * 17)+(5 * 0)) / 15=6,2$} \\
\hline & \multicolumn{14}{|c|}{$\sum \mathrm{WiXi}=((1 * 0)+(2 * 2)+(3 * 7)+(4 * 17)+(5 * 0)=93,0$} \\
\hline & \multicolumn{14}{|c|}{ Score $\% \mathrm{NEo}=(\Sigma \mathrm{WiXi} / 100) / \mathrm{Nqo}=(93 / 100) / 5=0,186=18,6 \%$} \\
\hline \multirow[t]{2}{*}{ Questão } & \multicolumn{2}{|c|}{ Excelente } & \multicolumn{2}{|c|}{ Ótimo } & \multicolumn{2}{|c|}{ Bom } & \multicolumn{2}{|c|}{ Ruim } & \multicolumn{2}{|c|}{ Péssimo } & $\begin{array}{c}M p=\sum \text { wixi } \\
/ \sum w i\end{array}$ & $\sum$ WiXi & Nqo & $\begin{array}{l}\text { Score } \\
\% \text { NEo }\end{array}$ \\
\hline & $\mathrm{Xi}$ & Wi & $\mathrm{Xi}$ & Wi & $\mathrm{Xi}$ & Wi & $\mathrm{Xi}$ & $\mathrm{Wi}$ & $\mathrm{Xi}$ & $\mathrm{Wi}$ & & & & \\
\hline Q10 & 0 & 1 & 1 & 2 & 8 & 3 & 15 & 4 & 2 & 5 & 6,4 & 96,0 & 5,0 & 19,2 \\
\hline \multirow{3}{*}{ Cálculo } & \multicolumn{14}{|c|}{$M p=\sum$ wixi $/ \sum$ wi $=((1 * 0)+(2 * 1)+(3 * 8)+(4 * 15)+(5 * 2)) / 15=6,4$} \\
\hline & \multicolumn{14}{|c|}{$\sum \mathrm{WiXi}=(1 * 0)+(2 * 1)+(3 * 8)+(4 * 15)+(5 * 2)=96,0$} \\
\hline & \multicolumn{14}{|c|}{ Score $\%$ NEo $=(\Sigma \mathrm{WiXi} / 100) / \mathrm{Nqo}=(96 / 100) / 5=0,192=19,2 \%$} \\
\hline
\end{tabular}

Quadro 9. Estratificação seção Práticas Operacionais - Questões Q9 e Q10

Fonte: elaborada pelos autores (2020).

Uma organização como sistema aberto é possível, termodinamicamente considerando que o aumento da ordem gere a redução da entropia e pode tender a um estado de organização, passando de um nível inferior a um superior, dependendo das condições do sistema e a aprendizagem é o fator que leva a essa condição. Dessa maneira, uma analogia ao desequilíbrio na comunicação empresarial poderia ser compensada pela valorização do conhecimento.

\section{CONCLUSÕES}

O estudo comprovou que os sistemas abertos, como sistemas organizacionais, podem reduzir ou aumentar a entropia. O conceito de entropia é por si só um indicador do estado do sistema que está relacionado com o estado de diferentes fatores que interagem com as organizações e o estudo demonstra como a entropia pode ser uma medida de desorganização do sistema aberto "organização empresarial".

Ainda que na literatura encontre-se visões diferentes sobre a aplicação dos estudos da segunda lei da termodinâmica em sistemas humanos abertos, há evidências de que tal aplicação pode ser exequível no que tange a abordagem deste estudo de maneira qualitativa.

O estudo confirmou que o entendimento de como a energia afeta o contexto organizacional é a essência do sistema de gestão, quando através dessa compreensão pode-se criar mecanismos para enfrentar os riscos e aproveitar novas oportunidades, trazendo equilíbrio para o sistema organizacional.

Finalmente foi desenvolvido um método de avaliação quali-quanti de gestão organizacional, método Neo, sob a ótica da entropia, tendo como base os princípios qualitativos da entropia. Pode-se concluir que a abordagem qualitativa embasou o desenvolvimento de um método de avaliação para elevar o nível de compreensão das práticas de gestão organizacional sob a ótica da entropia em sistemas abertos.

\section{REFERÊNCIAS}

Ali, F. et al. 2017. Size, Value and Business Cycle Variables. The Three-Factor Model and Future Economic Growth: Evidence from an Emerging Market. Economies 6, 1:1-14. https://doi. org/10.3390/economies6010014

Almeida-Santos, P.S. et al. 2014. Utilização da entropia informacional na seleção de indicadores financeiros mais relevantes para toma: o caso dos estados brasileiros. Perspectivas em Ciência da Informação 19, 2:83-105. https://doi. org/10.1590/1981-5344/1780

Annila, A.; Salthe, S. 2009. Economies evolve by Energy Dispersal. Entropy 11, 4:603-633. https://doi.org/10.3390/ e11040606

Araújo, U.P. et al. 2015. Desafiando a interdisciplinaridade na ciência administrativa: o caso da entropia. Cadernos EBAPE. BR 13, 4. https://doi.org/10.1590/1679-395131772

Barrett, R. 2010a. High Performance: It is all about entropy. Waynesville: Barrett Value Centre.

Barrett, R. 2010b. Fundamentals of Cultural Transformation: Implementing whole system change. Waynesville: Barrett Value Centre.

Ben, N.A. 2016. Entropy Demystified: The Second Law Reduced to Plain Common Sense. 2. ed. Singapura: World Scientific Publishing Company.

Bolisani, E., and Bratianu, C. 2018. Understanding the future for strategy formulation. In Bolisani, E. and Bratianu, C. Emergent knowledge strategies: Strategic thinking in knowledge management (p. 73-96). Cham: Springer International Publishing.

Bruyn, P. et al. 2014. Confirming Design Guidelines for Evolvable Business Processes Based on the Concept of Entropy. International Academy, Research, and Industry Association, Wilmington, p. 341-352.

Ceptureanu, E.G. et al. 2017. Relationship between Entropy, Corporate Entrepreneurship and Organizational Ca-pabilities in Romanian Medium Sized Enterprises. Entropy 19, 8:412429. https://doi.org/10.3390/e19080412 
Chang, Y. 2013. Social Thermodynamics, Social Hydrodynamics and Some Mathematical Applications in Social Sciences. International Journal of Modern Social Sciences 2, 2:94-108.

Chappell, D.; Dewey, T.G. 2015. Defining the Entropy of Hierarchical Organizations. Complexity, Governance \& Networks 1, 2:41-56. https://doi.org/10.7564/14-CGN17

Chun, X.Y. et al. 2013. Organization Theories: From Classical to Modern. Journal of Applied Sciences 13: 4470-4476. https:// doi.org/10.3923/jas.2013.4470.4476

Foster, J.B.; Burkett, P. Classical marxism and the second law of thermodynamics. Organization \& Environment 21, 1. https://doi.org/10.1177/1086026607313580

Gohil, S.; Deshpande, P. 2014. A Framework to Map a Practice as Organization Development. Procedia Economics and Finance 11, 218-229. https://doi.org/10.1016/S22125671(14)00190-7

Gray, D.E. 2013. Pesquisa no Mundo Real. 2. ed. Porto Alegre: Penso.

Grecio, N.O. 2016. Termodinâmica: um tutorial para entendimento do conceito de entropia. Dissertação, Instituto de Estudos Avançados e Estratégicos, Universidade Federal de São Carlos, São Carlos.

Hongkun, L. et al. 2016. The improved distribution method of negentropy and performance evaluation of CCPPs based on the structure theory of thermoeconomics. Applied Thermal Engineering 95, 5:64-75. https://doi.org/10.1016/j.applthermaleng.2015.11.052

Jing, D. 2011. The Study on Business Growth Process Management Entropy Model. Physics Procedia 24, Part C:2105-2110. https://doi.org/10.1016/j.phpro.2012.02.309

Johnson J.J. et al. 2013. A Theory of Emergence and Entropy in Systems of Systems. Procedia Computer Science 20, 283-289. https://doi.org/10.1016/j.procs.2013.09.274

Kümmel, R. 2016. The Impact of Entropy Production and Emission Mitigation on Economic Growth. Entropy 18, 3:75. https://doi.org/10.3390/e18030075

Lee, H. 2010. Leadership Success Factors: Examining Leadership Qualities by Personal Entropy. Barrett Values Centre. https://myctt.valuescentre.com/sites/default/files/wysiwyg-images/Leadership_Success_Factors.pdf

Martínez-Berumen, H.A.; López-Torres, G.C.; Romo-Rojas, L. 2014. Developing a Method to Evaluate Entropy in Organiza- tional Systems. Procedia Computer Science 28, 389-397. https://doi.org/10.1016/j.procs.2014.03.048

Markina, I.; Dyachkov, D. 2014. Entropy Model Management of Organization. Poltava National Technical Yurii Kondratuyk University.

Martínez-Berumen, H.A. et al. 2014. Developing a Method to Evaluate Entropy in Organizational Systems. Procedia Computer Science 28, 389-397. https://doi.org/10.1016/j. procs.2014.03.048

Mcauley, J. et al. 2013. Organization Theory: Challenges and Perspectives. 2. Ed. Philadelphia: Trans-atlantic Publications, Inc

Olyaiy, M. 2015. Development of process-based entropy measurement: Framework for organization, Malaysia. Tese, Universiti Teknologi.

Prahalad, C.K. 2010. The Responsible Manager. Harvard Business Review. https://hbr.org/2010/01/column-the-responsible-manager

Quarati, P. et al. 2016. Negentropy in Many-Body Quantum Systems. Entropy 18, 2:18-63. https://doi.org/10.3390/ e18020063.

Rãdulescu, R. 2013. The development of a business strategy system from an entropic point of view. Bucharest University of Economic Studies, Bucharest.

Rezende, J.F. et al. 2016. Plataformas para gestão do conhecimento: estudo de caso sobre a ativação do valor de excedentes cogn. Perspectivas em Gestão \& Conhecimento 6, 1:72-88.

Santamaría-Bonfil, G. et al. 2016. Measuring the complexity of continuous distributions. Entropia 18, 3. https://doi. org/10.3390/e18030072

Stephen, D.G.; Dixon, J.A. 2009. Dynamics of Representational Change: Entropy, Action, and Cognition. Journal of Experimental Psychology 35, 6:1811-1832. https://doi.org/10.1037/ a0014510

Strauss, A.; Glaser, G.B. 1967. The Discovery of Grounded Theron: Strategies for Qualitative. Aldine, Chicago.

Ursacescu, M.; Cioc, M. 2016. Evaluation of Information Entropy in Organizational System. Management and Economics Review 1, 2:82-91.

Vasconcellos, Á.R. et al. 2015. Complexidade, auto-organização e informação em sistemas dinâmicos. Revista Brasileira de Ensino de Física 37, 2:2314-2330. https://doi.org/10.1590/ S1806-11173721806

Recebido: 25 ago. 2020

Aprovado: 02 nov. 2020

DOI: 10.20985/1980-5160.2020.v15n3.1671

Como citar: Carvalho, C.L.; Costa, S.R.R. (2020). Gestão organizacional: proposta de um método de avaliação sob a ótica do conceito de entropia organizacional. Revista S\&G 15, 3, 277-293. https://revistasg.emnuvens.com.br/sg/ article/view/1671 